\title{
CERRO MACARENO (LA RINCONADA, SEVILLA): NUEVOS DATOS SOBRE SU SECUENCIA DE OCUPACIÓN Y RASGOS CONSTRUCTIVOS
}

\author{
CERRO MACARENO (LA RINCONADA, SEVILLA): NEW DATA ON ITS \\ OCCUPATION SEQUENCE AND ITS CONSTRUCTIVE FEATURES
}

\author{
FRANCISCO JOSÉ GARCÍA FERNÁNDEZ \\ Profesor Titular de Universidad, Departamento de Prehistoria y Arqueología, Facultad de Geografía e Historia, \\ Universidad de Sevilla. Dirección postal: c/ María de Padilla s/n, 41004, Sevilla \\ Telf.: 954551414. Correo-e: fjgf@us.es. (D https://orcid.org/0000-0002-4978-8818 \\ Researcher ID: https://publons.com/researcher/K-3364-2014
}

\begin{abstract}
Resumen: La intervención arqueológica llevada a cabo en 2017 en Cerro Macareno ha proporcionado un ingente caudal de información que corrobora, pero también matiza, los datos aportados por las excavaciones de urgencia realizadas en este yacimiento a mediados de la década de los setenta. La metodología aplicada se ha basado en todo momento en técnicas no destructivas o de bajo impacto sobre los restos. Entre las tareas desarrolladas destaca la limpieza de perfiles y el estudio de las secciones estratigráficas resultantes en diferentes puntos del yacimiento, que han permitido llevar a cabo un análisis comparado de las distintas secuencias obtenidas. Estas se han cotejado posteriormente con las plantas y secciones de las antiguas excavaciones publicadas, una vez que han sido digitalizadas y georreferenciadas, especialmente el sondeo estratigráfico efectuado por M. Pellicer y su equipo en 1976. Como resultado, contamos con una sistematización de la documentación existente y una actualización del conocimiento sobre los niveles de ocupación conservados y su cronología. Asimismo, se han podido recopilar nuevos datos sobre las formas arquitectónicas, los materiales y técnicas constructivas, así como sobre las pautas de edificación-reparación-reconstrucción de los edificios.

Palabras clave: Protohistoria, Bajo Guadalquivir, estratigrafía, cronología, urbanismo, arquitectura, técnicas constructivas.
\end{abstract}

\begin{abstract}
The archaeological intervention carried out in 2017 in Cerro Macareno has provided an enormous amount of information that corroborates and qualifies the data provided by the emergency excavations carried out in this site in the mid-seventies. The methodology applied has always been based on non-destructive techniques or low impact on the remains. Among the tasks developed, the cleaning of slopes and the study of the resulting stratigraphic sections in different points of the site stand out, which have allowed a comparative analysis of the different sequences obtained. Then, they have been compared with the plants and sections of the old excavations published, once they had been digitalised and georeferenced, especially the stratigraphic sounding carried out by M. Pellicer and his team in 1976. As a result, we have a systematization of the existing documentation and an update of the knowledge about the levels of occupation conserved and their chronology. Likewise, it has been possible to collect new data on architectural forms, materials and construction techniques, as well as on the building-repair-reconstruction guidelines of the buildings.
\end{abstract}

Key words: Protohistory, Lower Guadalquivir valley, stratigraphy, chronology, urbanism, architecture, construction techniques. 
Cerro Macareno es un gran tell protohistórico ubicado en el municipio de La Rinconada (Sevilla), junto a la barriada de San José. Se situaba originalmente sobre un suave promontorio formado por las terrazas bajas del Guadalquivir, en su margen izquierda y junto a un canal navegable del mismo, ocupado actualmente por el arroyo Almonázar. Ello le proporcionaba una posición privilegiada en relación con el sistema poblacional introducido por los fenicios a inicios de la Edad del Hierro y que se mantuvo con pocos cambios a lo largo del I milenio a.C. (Escacena 1983 y 1987; véase también Ferrer et al. 2008, Ferrer 2017, García Fernández 2017). El yacimiento pasó inadvertido para la arqueología hasta el inicio de su destrucción a principios de la década de los setenta, cuando su explotación como gravera levantó la voz de alarma entre aficionados e investigadores, que pusieron los primeros medios para su conservación y estudio, como se verá más adelante. A pesar de la paralización de las labores extractivas en 1975, su perímetro acabó reducido a menos de un tercio de su superficie original, que se llegó a estimar en $50000 \mathrm{~m}^{2}$ (Pellicer et al. 1983: 18). Hoy en día el yacimiento está constituido por dos cerros testigo separados por una lengua de tierra, correspondiente al antiguo frente de extracción de la gravera, con diferente nivel de conservación. La elevación oriental, la menos afectada por la acción de las máquinas, conforma una meseta regular de forma romboidal de aproximadamente $9000 \mathrm{~m}^{2}$ y $8 \mathrm{~m}$ de potencia máxima, conservando la superficie original del cerro y, por tanto, la mayor parte de los depósitos arqueológicos. Por el contrario, la elevación occidental, de unos $6500 \mathrm{~m}^{2} \mathrm{y}$ con una superficie más irregular, ya había sido parcialmente desmontada a mediados de los años setenta, por lo que solo conserva unos $2 \mathrm{~m}$ de potencia arqueológica, correspondientes a los estratos inferiores (fig. 1).

Paradójicamente, el cierre de la cantera no supuso un avance en las investigaciones, que carecieron de continuidad más allá del estudio de los resultados de las ya realizadas o la revisión de algunos materiales procedentes de las mismas. Solo cuarenta años después de las últimas excavaciones, dirigidas por M. Pellicer (Pellicer et al. 1983), se han retomado las investigaciones en Cerro Macareno a partir de un convenio suscrito entre el Departamento de Prehistoria y Arqueología de la Universidad de Sevilla y el Ayuntamiento de La Rinconada, con un triple objetivo: avanzar en el conocimiento científico del yacimiento y su entorno, garantizar su adecuada protección y conservación y explorar las estrategias más adecuadas de integración urbanística y puesta en valor de este espacio. Para ello se planteó una primera intervención arqueológica puntual en 2017 destinada a realizar un diagnóstico previo mediante técnicas no invasivas (prospección superficial, prospección geofísica, limpieza de perfiles y registro de estructuras emergentes), que permitiera valorar el estado de los restos conservados y su potencial científico, así como aportar nuevos datos sobre la secuencia de ocupación y la organización urbana del primitivo asentamiento con objeto de orientar actuaciones futuras en el marco de proyectos de investigación sistemáticos. Los resultados obtenidos son coherentes con los proporcionados por las excavaciones anteriores, pero introducen también interesantes matices en lo que se refiere a la evolución del hábitat y su distribución espacial, la entidad o función de las estructuras y sus características arquitectónicas y constructivas (v. García Fernández et al. e.p.).

\section{ANTECEDENTES}

Las primeras noticias que se tienen de Cerro Macareno se remontan a inicios de la década de los setenta, cuando unos vecinos de la cercana localidad de Brenes dan a conocer la existencia de restos arqueológicos en la zona, comunicándoselo al Departamento de Prehistoria y Arqueología de la Universidad de Sevilla. Las visitas de algunos de sus miembros y de M. Ponsich, que por aquel entonces estaba elaborando el primer volumen de su obra Implantation rurale Antique sur le Bas-Guadalquivir (Ponsich 1974), dieron lugar a las primeras noticias científicas que se tienen del mismo. Durante esos mismos años se había producido también el depósito, en el Museo Arqueológico de Sevilla, de algunos materiales de esa procedencia, lo que incrementó el interés por este lugar (Fernández-Chicarro 1974).

No obstante, fue la sistemática destrucción del yacimiento con motivo de su puesta en explotación como cantera de áridos la que despertó la atención de la comunidad científica y la que determinó el inicio de su estudio y las primeras tentativas de protección. Así pues, a finales de 1973 los terrenos ocupados por el yacimiento fueron incluidos en el Decreto 3383/1973, de 21 de diciembre, por el que se declaran de utilidad pública, a efectos de expropiación forzosa, diversos yacimientos arqueológicos de excepcional importancia para el conocimiento del reino de Tartessos, en el Bajo Guadalquivir (García y Del Espino 2019). Al año siguiente, tras una visita de J. Maluquer de Motes, por aquel entonces Comisario General de Excavaciones Arqueológicas, se organizó la primera campaña de excavaciones 

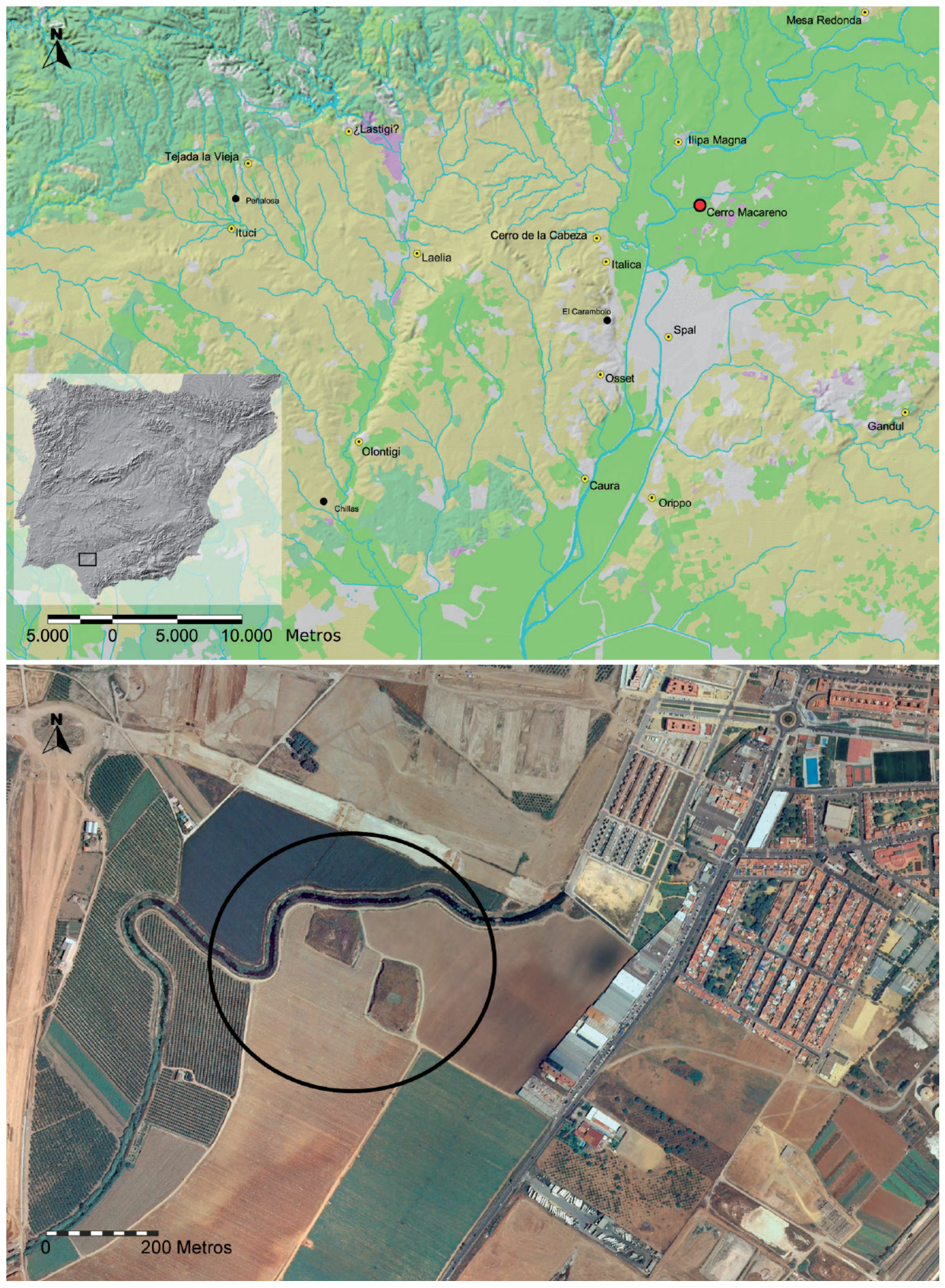

Figura 1. Ubicación de Cerro Macareno en el contexto del poblamiento protohistórico del Bajo Guadalquivir (arriba) e imagen aérea del yacimiento (abajo), a partir de la Ortofotografia Básica Color de Andalucía 2010-2011 (<http://www. ideandalucia.es/wms/ortofoto2010>).

ISSN: $1133-4525$ ISSN-e: $2255-3924$ 


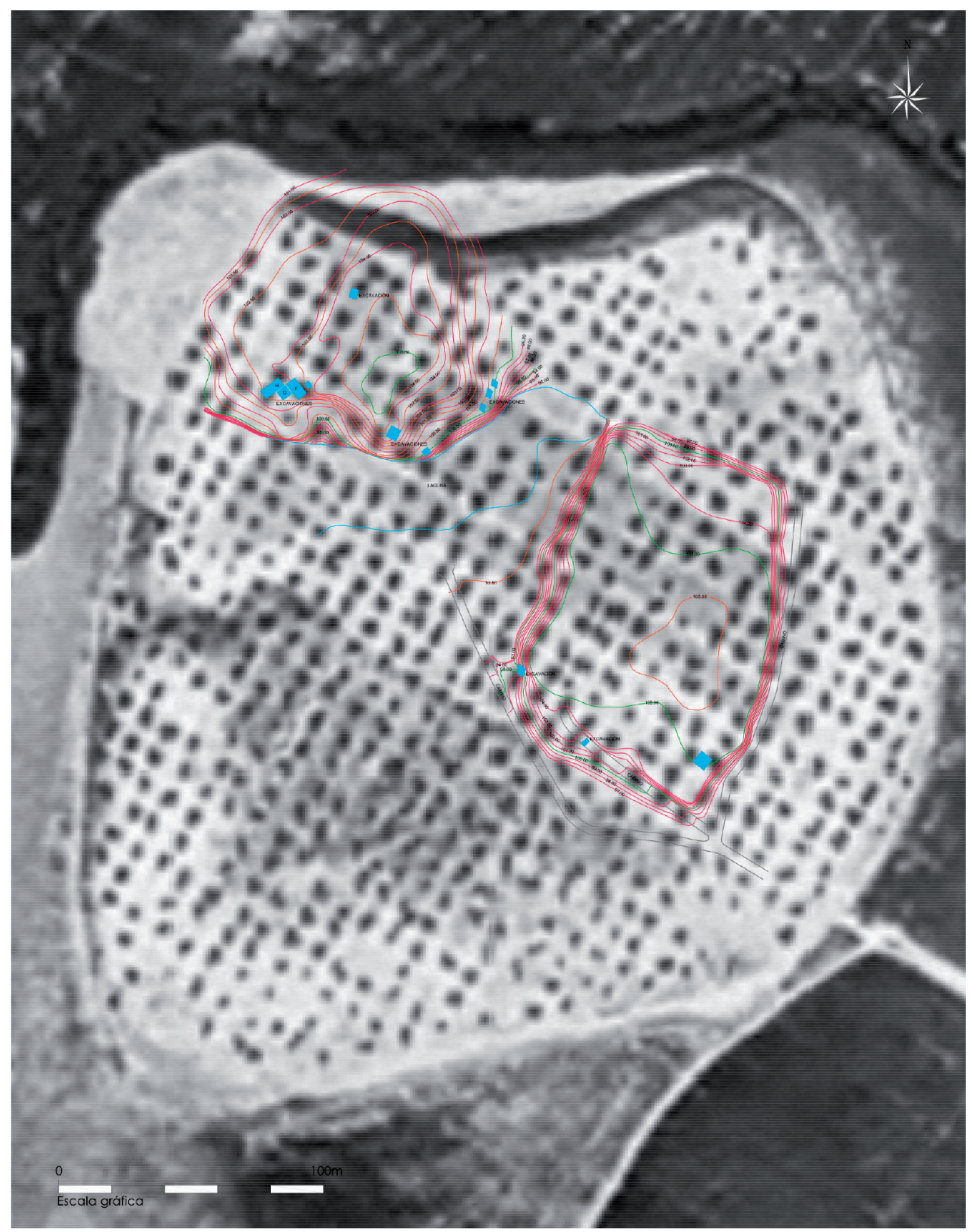

Figura 2. Levantamiento topográfico realizado en 1974, con indicación de los cortes practicados entre 1974 y 1976 (a partir de Fernández Gómez et al. 1979), superpuesto a la imagen del yacimiento previa a su destrucción obtenida de la Ortofoto de Andalucía 1956-57 (Vuelo General de España de 1956). 


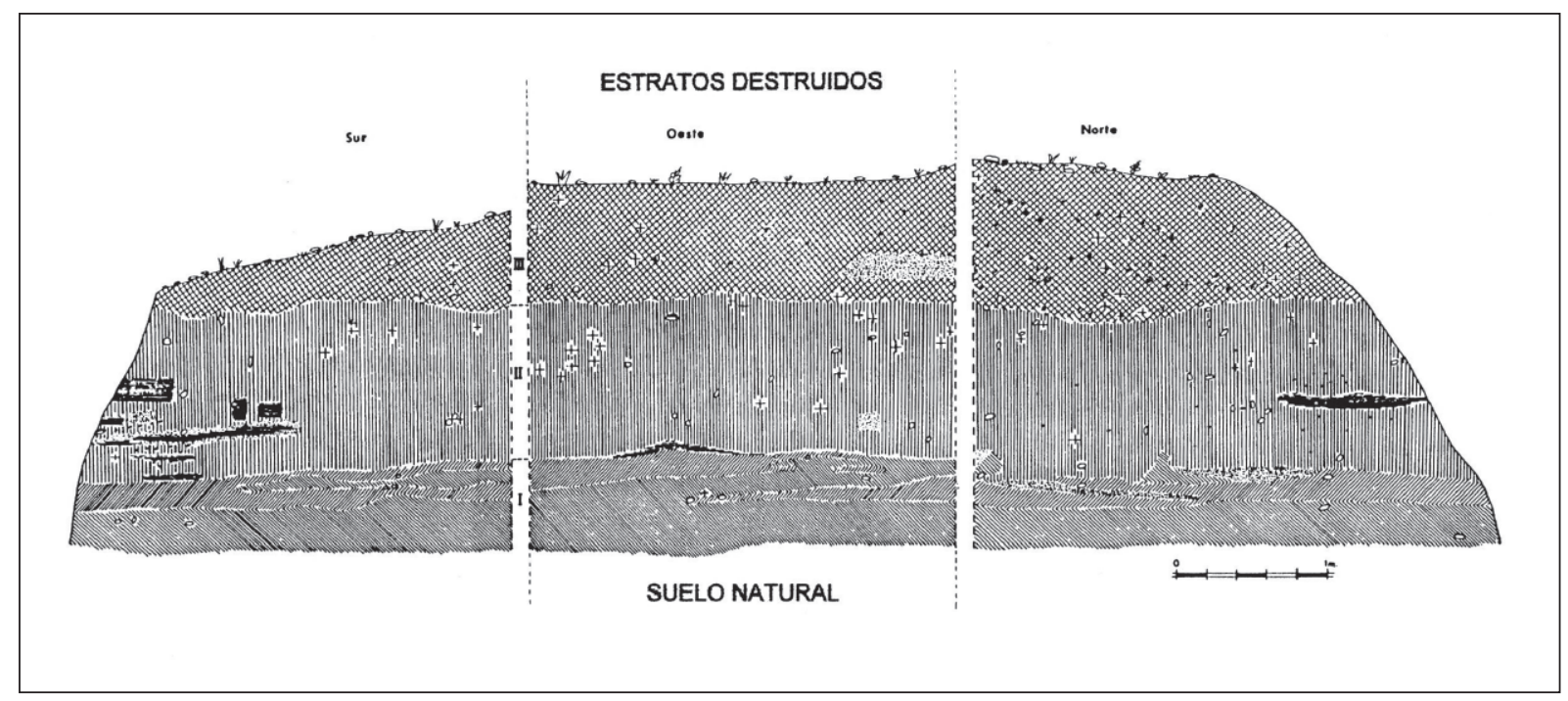

Figura 3. Secciones estratigráficas obtenidas en el corte C (elevación occidental) de 1974 (Ruiz Mata y Vallejo 2002: fig. 2).

a cargo de un equipo de arqueólogos de la Universidad Autónoma de Madrid, el Museo Arqueológico de Sevilla y la Universidad de Sevilla (Fernández Gómez et al. 1979: 11).

La intervención se inició con la excavación, durante el verano de 1974, de los cortes A, B, C, D y E, localizados en distintos puntos de la elevación occidental, así como con una limpieza de perfiles en la elevación oriental (corte F), con el fin de poder correlacionar estratigráficamente ambos sectores (fig. 2). A principios de noviembre del mismo año se reanudaron las excavaciones en la elevación occidental, en un sector cuya destrucción era inminente, pues aún no se habían paralizado las labores extractivas de la cantera. Aquí se abrieron otros tres cortes ( $\mathrm{F}, \mathrm{G}$ y $\mathrm{H})$, de los que finalmente se encargó el equipo del Museo Arqueológico de Sevilla (fig. 2). Esta segunda fase se interrumpió a finales del mismo mes a causa de las lluvias y no se pudieron retomar debido a la negativa de los propietarios y del contratista hasta que no se resolviera el expediente de expropiación incoado (Fernández Gómez et al. 1979: 11).

$\mathrm{Al}$ año siguiente, en 1975, se programó una segunda campaña, aunque nunca llegó a emprenderse debido a las mismas razones. Finalmente, en 1976 y con el beneplácito del contratista, M. Pellicer obtuvo el permiso para la realización de una nueva intervención con el fin de recabar la información necesaria para agilizar los trámites iniciados. En este caso la excavación se llevó a cabo en el talud SE de la elevación oriental, una zona que aparentemente ofrecía una secuencia completa e inalterada de las distintas fases de ocupación del cerro (fig. 2). El corte V-20, que recibió ese nombre a partir de la nueva organización del yacimiento en un sistema cartesiano de cuadrículas planteada por el equipo de Pellicer (Pellicer et al. 1983: 18), constituye la última excavación realizada hasta la fecha.

Lamentablemente, la publicación de los resultados de estas intervenciones fue muy irregular. Los cortes A, B y D quedaron inéditos; por el contrario, el estudio de los cortes E, F y G, a cargo del equipo del Museo Arqueológico de Sevilla, vio rápidamente la luz (Fernández Gómez et al. 1979). La limpieza de perfiles realizada en la elevación oriental constituyó la Memoria de Licenciatura de J.C. Martín de la Cruz, publicándose también de forma inmediata (Martín de la Cruz 1976), mientras que el sondeo estratigráfico efectuado en 1976 en el mismo sector por el equipo de M. Pellicer dio lugar algunos años después a una monografía que se convertiría en un referente para el estudio de la secuencia cultural protohistórica del Bajo Guadalquivir (Pellicer et al. 1983). A partir de ahí habría que esperar dos décadas para que D. Ruiz Mata emprendiera la publicación de los restantes cortes, el H.I y H.II (Ruiz Mata y Córdoba 1999) y el corte C (Ruiz Mata y Vallejo 2002).

Este último, ofreció una estratigrafía de $2,5 \mathrm{~m}$ de potencia máxima (fig. 3), donde pudieron distinguirse tres estratos bastante homogéneos, sin restos constructivos y con una cronología que puede situarse en torno al s. VI a.C. a partir del material exhumado en los mismos, exclusivamente cerámico (Ruiz Mata y Vallejo 2002: 199). Paralelamente, el corte E se excavó hasta 


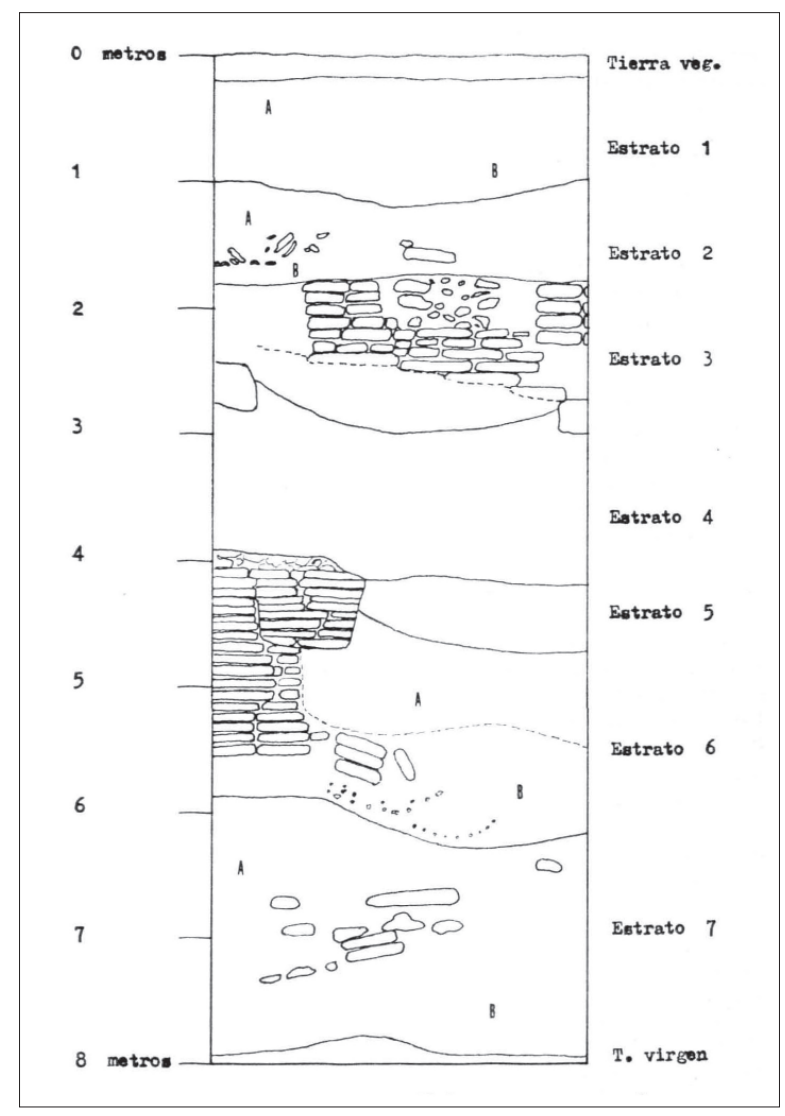

Figura 4. Sección estratigráfica obtenida en el corte F (elevación oriental) de 1974 (Martín de la Cruz 1976: fig. 2).

una profundidad de 1,45 m. En ese punto apareció un potente suelo de habitación que abarcaba prácticamente toda la cuadrícula, asociado a restos de muros de adobe y a un hogar sobre el que se superponía un depósito de abandono y derrumbe formado por escombros, tierra y ceniza (Fernández Gómez et al. 1979: 14-23).

Por su parte, los cortes F, G y H dieron con una amplia área artesanal asociada a un posible espacio de hábitat anejo (fig. 5). Este se pudo registrar únicamente en el corte $\mathrm{F}$, dividido en dos por un potente muro que lo atravesaba en sentido NE-SO y al cual se unía otro perpendicular en el centro de la cuadrícula, conformando dos ámbitos perfectamente delimitados: uno exterior, relacionado con las estructuras de producción de los cortes $\mathrm{G}$ y $\mathrm{H}$, y otro interior, separado a su vez en dos estancias distintas y bien pavimentadas (Fernández Gómez et al. 1979: 23-26). Sin embargo, es la presencia de un conjunto de hornos de cerámica lo que determina la función de este sector. En el corte G se documentó la cámara de combustión de un horno de planta ovalada y pilar central, con la boca abierta al este (Fernández
Gómez et al. 1979: 26-28); mientras que en los cortes H.I y H.II se excavaron otras dos estructuras de similares características aunque de distinto tamaño (Ruiz Mata y Córdoba 1999). Tanto uno como los otros estaban asociados a dos hoyos que se extendían hacia la cuadrícula F, rellenos de capas de ceniza, tierra, adobe y restos de cerámica procedentes de la limpieza de los hornos (Fernández Gómez et al. 1979: 25). Estos materiales y otros vinculados a sus niveles de construcción $\mathrm{y}$ uso, permitieron fechar este complejo alfarero entre mediados/finales del s. V y mediados del IV a.C. (García Fernández y García Vargas 2012: 21).

Por último, el corte V-20 de Pellicer, con 4 x $4 \mathrm{~m}$ de lado y 7,50 m de potencia máxima (fig. 6), ofreció una secuencia completa de la ocupación del cerro que se inicia a mediados del s. VIII y se prolonga ininterrumpidamente hasta principios del I a.C. (Pellicer et al. 1983). Aquí se pudieron registrar hasta siete episodios constructivos, representados por una sucesión de muros, pavimentos, hogares, etc., algunos de ellos con varias fases de refacción, asociados siempre a niveles domésticos, que contribuyeron a reconstruir la evolución del poblado, tanto en lo que se refiere a su cultura material como sus las formas de vida. No en vano, el estudio sistemático de los contextos cerámicos exhumados en las distintas fases sentó las bases para la clasificación de las producciones regionales de la Edad del Hierro (Pellicer 1982, Pellicer et al. 1983) y, sobre todo, para la primera seriación tipológica de las ánforas prerromanas del valle del Guadalquivir (Pellicer 1978). Asimismo, se examinaron los restos faunísticos (Amberger 1985) y se emprendieron las primeras analíticas de pastas, con el fin de determinar el origen y las características de estas producciones (González García et al. 1985, González Vilches et al. 1985a, b, 1988).

Desde entonces y hasta el inicio del actual proyecto no se han llevado a cabo nuevas intervenciones sobre el yacimiento, a excepción de la prospección arqueológica superficial realizada en 2007 con motivo de la redacción del PGOU de La Rinconada (Jiménez 2010). Este estudio se centró en los sectores recientemente calificados como Suelo Urbanizable, que afectaban tanto a los terrenos ocupados por el Cerro Macareno como a su entorno más inmediato, y tuvo entre sus principales objetivos establecer la delimitación original del primitivo oppidum de cara a garantizar su protección futura. Combinando el trabajo de campo con el análisis de las fotografías aéreas, desde el Vuelo Americano de 1956 hasta las más recientes, se pudo reconstruir cartográficamente el perímetro del montículo antes de su destrucción y avanzar en la determinación de posibles áreas y fases de ocupación, 


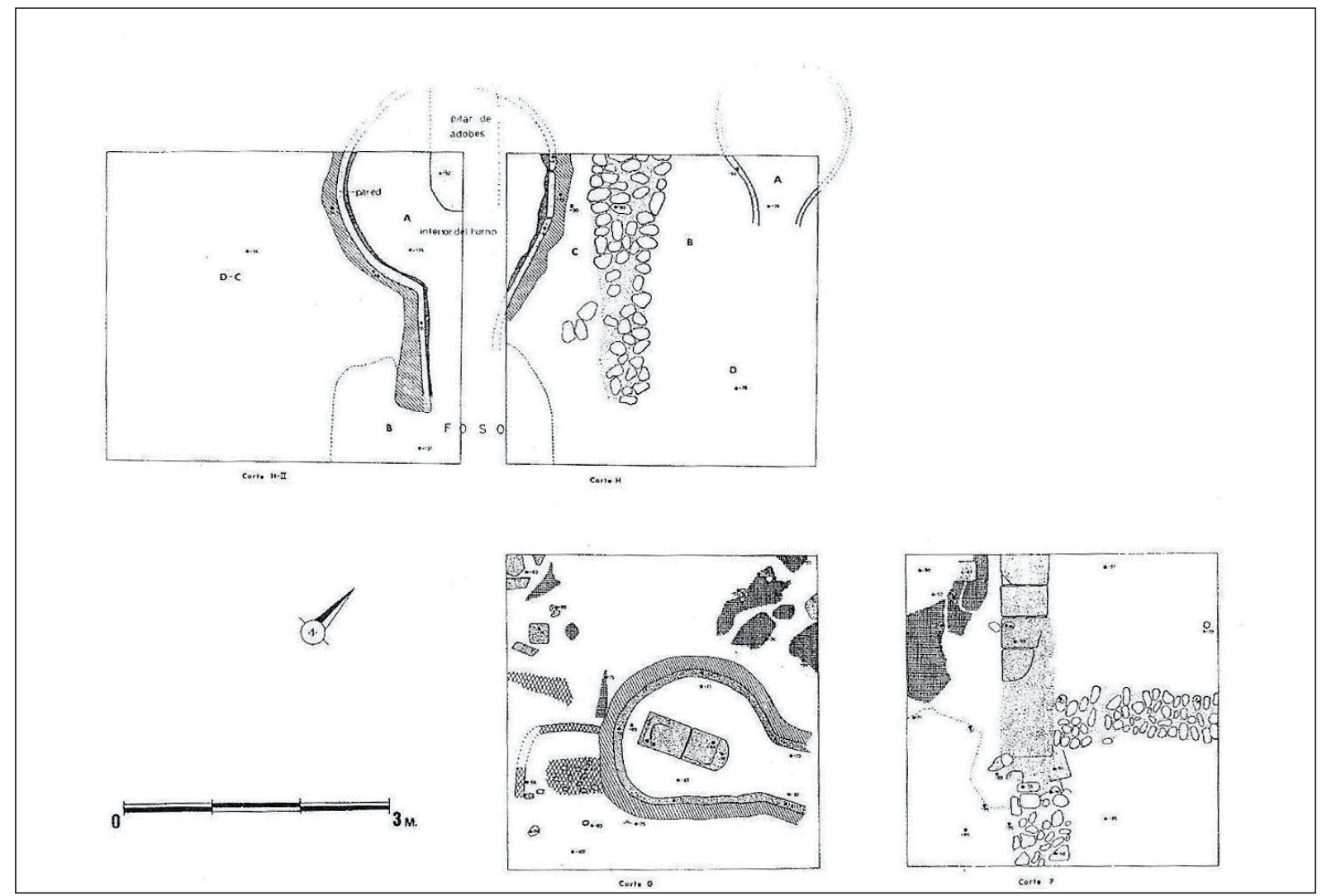

Figura 5. Planta de las estructuras documentadas en los cortes F, G y H (elevación occidental) de 1974 (Ruiz Mata y Córdoba 1999: fig. 3).

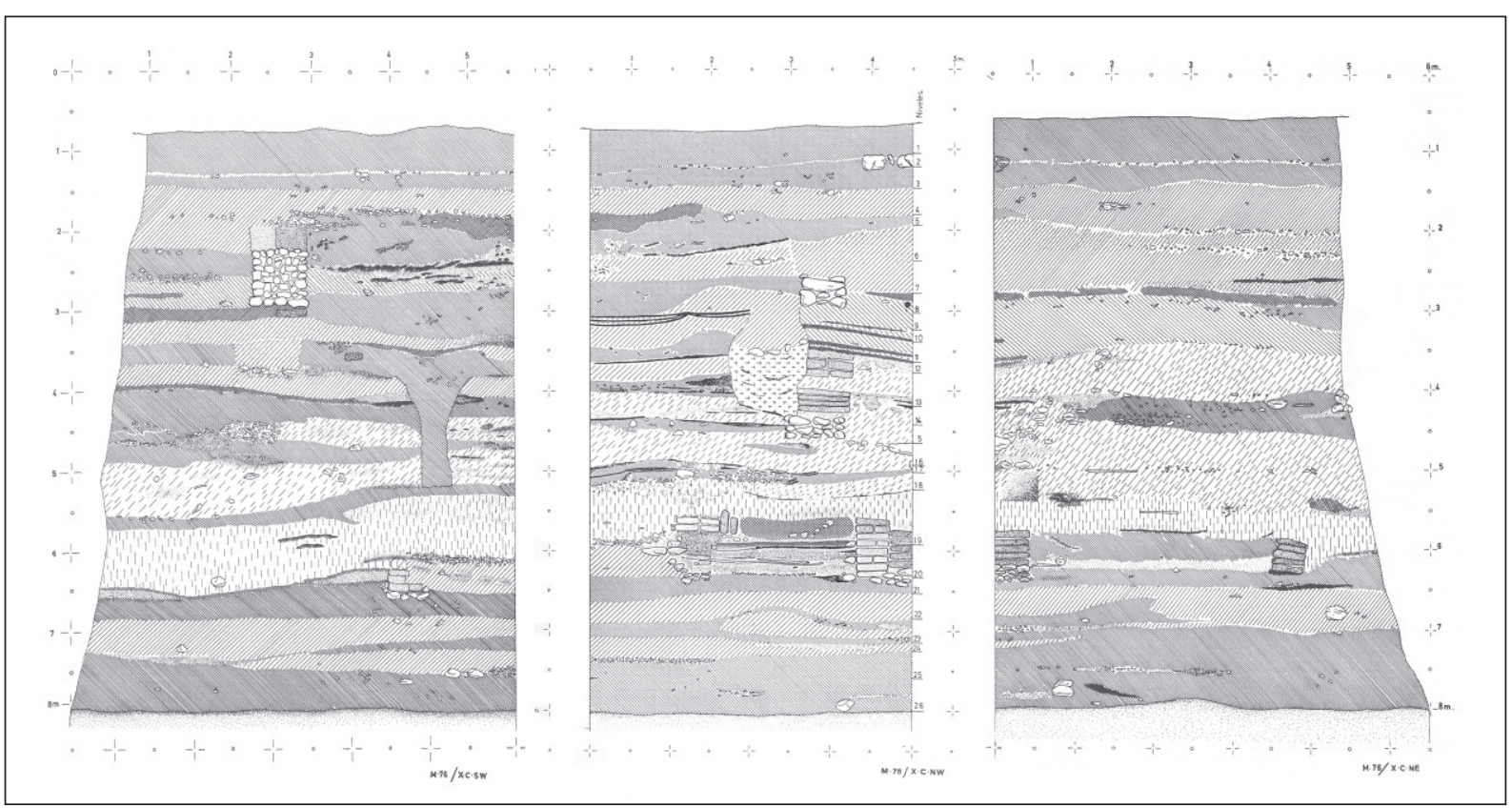

Figura 6. Sección estratigráfica obtenida en el corte V-20 (elevación oriental) de 1976 (Pellicer et al. 1983: figs. 5-7).

ISSN: 1133-4525 ISSN-e: 2255-3924 
lo que ha servido de base indispensable para el actual proyecto (Jiménez 2010: 3801-3802). A lo largo de estas últimas décadas sí han sido frecuentes, en cambio, los estudios sobre los materiales procedentes de las antiguas campañas, especialmente los cerámicos, lo que es indicativo del interés que sigue despertando este yacimiento entre los investigadores y las expectativas sobre el potencial científico de los restos conservados.

\section{LA CAMPAÑA DE 2017: METODOLOGÍA Y DESARROLLO DE LOS TRABAJOS}

Como se ha dicho más arriba, en esta intervención de diagnóstico se han priorizado las actividades menos invasivas con objeto de extraer la máxima información sobre el yacimiento con el mínimo impacto sobre los restos.

\subsection{Prospección superficial}

La primera actividad fue la inspección visual del yacimiento y su entorno, utilizando como base la información procedente de trabajos anteriores, especialmente los resultados de la prospección llevada a cabo en 2007 (Jiménez 2010). Además de la revisión de los límites del bien y de los sectores conservados, se pudo comprobar la potencia estratigráfica de las dos elevaciones principales, el estado de conservación de sus perfiles, la regularidad de su superficie, accesibilidad, tipo y densidad de vegetación, etc.

\subsection{Levantamiento planimétrico}

Paralelamente se realizó un nuevo levantamiento de todo el yacimiento y sus accesos a partir de las bases cartográficas existentes (fig. 7). Ello permitía disponer de un soporte digital de referencia más preciso donde integrar y gestionar la información generada por el proyecto y los recursos cartográficos utilizados. Asimismo, a este soporte se ha ido incorporando el registro gráfico procedente de las intervenciones arqueológicas anteriores mediante la digitalización de las planimetrías y su transformación en capas vectoriales.

\subsection{Prospección geofísica}

Una de las actividades principales fue la realización de una prospección magnética de la superficie de las dos elevaciones, con el fin de contar con una primera lectura de la tipología, función y distribución de las estructuras subsuperficiales, así como poder valorar su potencia, complejidad y estado de conservación. Asimismo, se realizaron también tomas de datos con el georradar para corroborar la información proporcionada por el magnetómetro y afinar la lectura de las irregularidades detectadas en superficie. A pesar de ello los resultados fueron muy desiguales entre una elevación y otra, debido en parte a la naturaleza de los materiales subyacentes y su complejidad estratigráfica, lo que exige explorar y aplicar en el futuro otras técnicas geofísicas sobre los mismos sectores.

\subsection{Limpieza de perfiles y registro de estructuras}

Con objeto de sacar el máximo provecho a los cortes dejados por las máquinas excavadoras en el contorno de los dos cerros testigo conservados, se planteó la limpieza y documentación de una serie de perfiles previamente seleccionados y delimitados. Para evitar el deterioro de los mismos y garantizar un registro más amplio no se llevaron a cabo rectificaciones manuales de su superficie, mientras que el rebaje de los taludes se redujo a lo estrictamente necesario para trabajar sobre ellos. Asimismo, la altura de los cortes limitaba el trabajo en los niveles superiores de la estratigrafía dentro de los márgenes de seguridad establecidos, por lo que finalmente se sacrificó la obtención de secuencias verticales continuas y homogéneas por la documentación de secciones extensas y horizontales.

Antes fue preciso dividir el perímetro de los dos cerros en sectores que facilitaran la organización de las tareas y la localización de las unidades de intervención. Para ello se siguieron los siguientes criterios: respetar la propia geometría de los cerros, definir tramos cuyos perfiles presentasen características y condiciones de conservación parecidas, y tratar de mantener sectores más o menos homogéneos en tamaño. En la elevación oriental se delimitaron un total de 8 sectores de entre 35 y 55 m de longitud, numerados siguiendo el sentido contrario a las agujas del reloj, mientras que en la elevación occidental se establecieron 5 , correspondientes a los lados del polígono que lo conforma. Ante la imposibilidad de abarcar todos los sectores en una misma campaña se decidió dar prioridad a la elevación oriental debido al mejor estado de conservación de sus depósitos, con perfiles más potentes, mayor cantidad de estructuras visibles y la práctica ausencia de vegetación, en comparación con la elevación occidental. Finalmente se seleccionaron cuatro sectores situados en puntos opuestos del cerro (sectores 1, 4, 5 y 7), buscando tener 


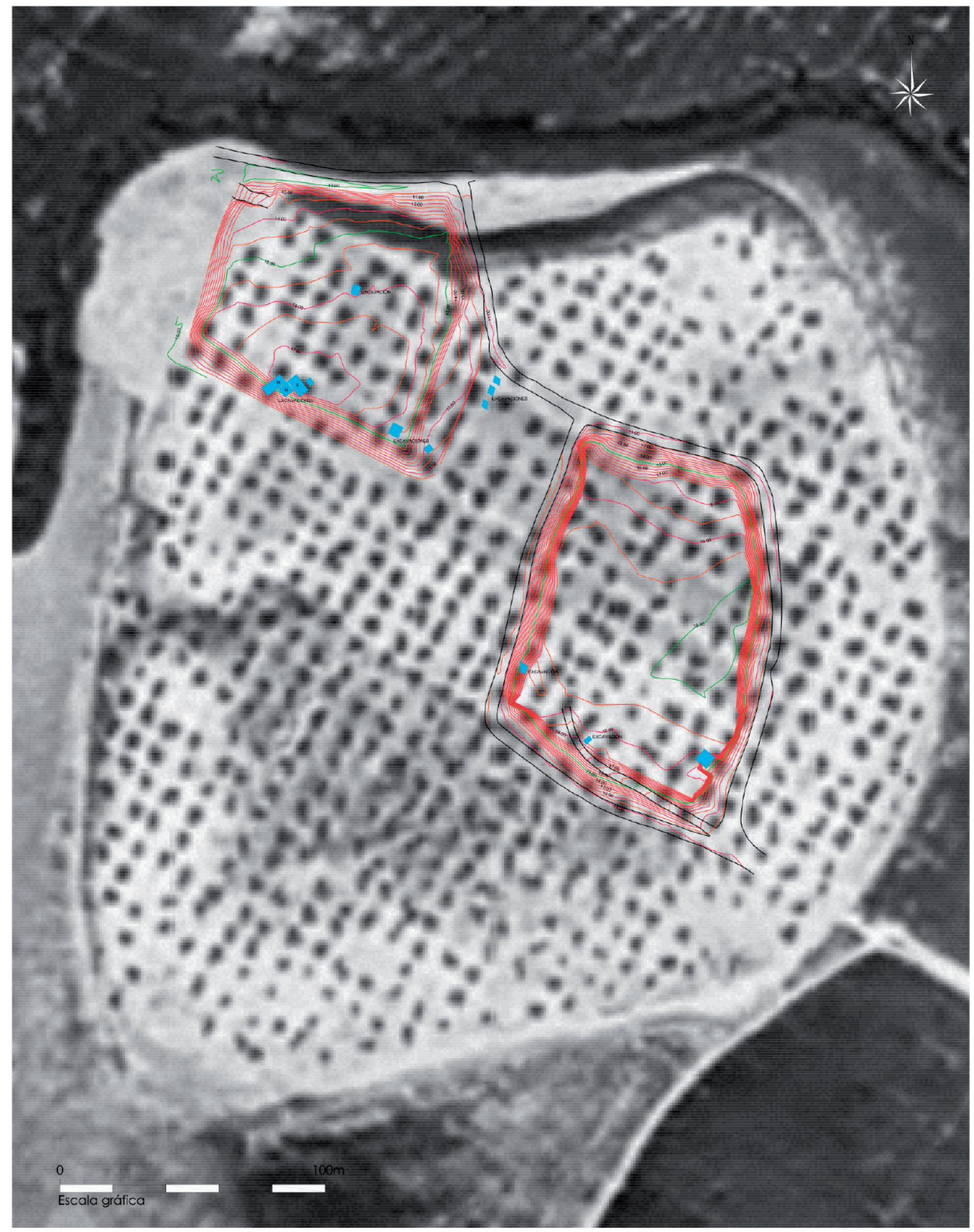

Figura 7. Nuevo levantamiento topográfico realizado en 2017, con indicación de los cortes practicados entre 1974 y 1976 , superpuesto a la imagen del yacimiento previa a su destrucción obtenida de la Ortofoto de Andalucía 1956-57 (Vuelo General de España de 1956).

ISSN: 1133-4525 ISSN-e: 2255-3924 


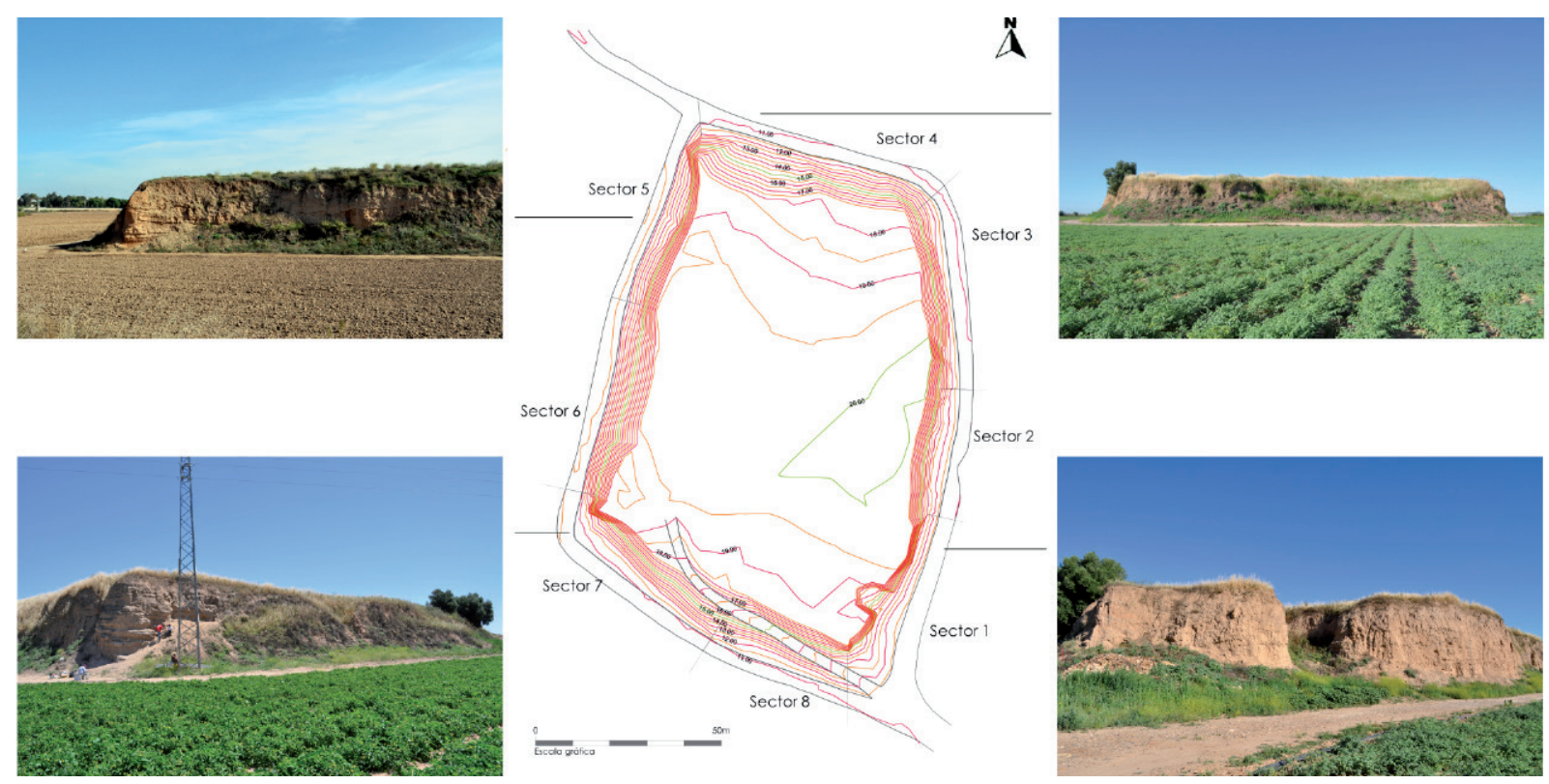

Figura 8. Detalle del nuevo levantamiento topográfico realizado en 2017 con indicación de los sectores en los que fueron divididos los perfiles de la elevación oriental y panorámica general de los sectores intervenidos $(1,4,5$ y 7$)$.

una muestra representativa de todo su perímetro para su comparación. Las unidades de intervención se establecieron en aquellos lugares que cumplían estos mismos criterios y ofrecían mejores posibilidades de establecer secciones amplias con el menor esfuerzo (fig. 8).

El procedimiento seguido en todas las unidades de intervención fue el mismo: delimitación del área de trabajo, limpieza superficial de los perfiles, identificación y delimitación de los elementos de interés (muros, pavimentos, instalaciones) y de las unidades deposicionales asociadas, documentación y registro gráfico (dibujo y fotografía), recogida de materiales, diagnóstico del estado de conservación y georreferenciación. Posteriormente se llevaron a cabo levantamientos tridimensionales en cada una de las unidades de intervención utilizando la técnica de la fotogrametría digital convergente, lo que permitió disponer de un registro más exhaustivo y preciso de los perfiles.

\section{ESTUDIO DE LAS SECCIONES ESTRATIGRÁFICAS}

Una síntesis de los resultados de esta intervención se presentó en el IX Congreso Internacional de Estudios Fenicios y Púnicos (García Fernández et al. e.p.), por lo que nos centraremos aquí en el estudio pormenorizado de las secciones estratigráficas obtenidas en las limpiezas de perfiles y su correlación con los datos aportados por las excavaciones realizadas en los años setenta, anteriormente descritas.

\subsection{Sector 1}

La sección obtenida en este sector fue la más amplia en extensión, tanto por las óptimas condiciones de trabajo que ofrecía el perfil como por los elementos constructivos que a priori se vislumbraban en el mismo. Se alcanzó una longitud total de $10,70 \mathrm{~m}$ y una potencia máxima de $3,80 \mathrm{~m}$, desde la cota 12,87 a la 16,66 m s.n.m. (fig. 9). Sin embargo, también ha sido la unidad de intervención más compleja, tanto por la intensa y prolongada dinámica de construcción/reparación/ amortización, como por la destrucción a la que fue sometido el perfil, dejando importantes lagunas estratigráficas en algunos puntos.

El nivel más antiguo detectado, a una cota de 13 m s.n.m. aproximadamente, es un relleno de arcilla y ceniza, de color grisáceo y poco compacto (UE-143), que parece amortizar a una estructura anterior, probablemente un muro de adobe color rojizo, que no se llegó a excavar, ya que se proyectaba en planta fuera del perfil (UE-153). Asociados a este aparecieron materiales relativamente antiguos, en concreto dos fragmentos de cerámica modelada a mano de acabado tosco, 


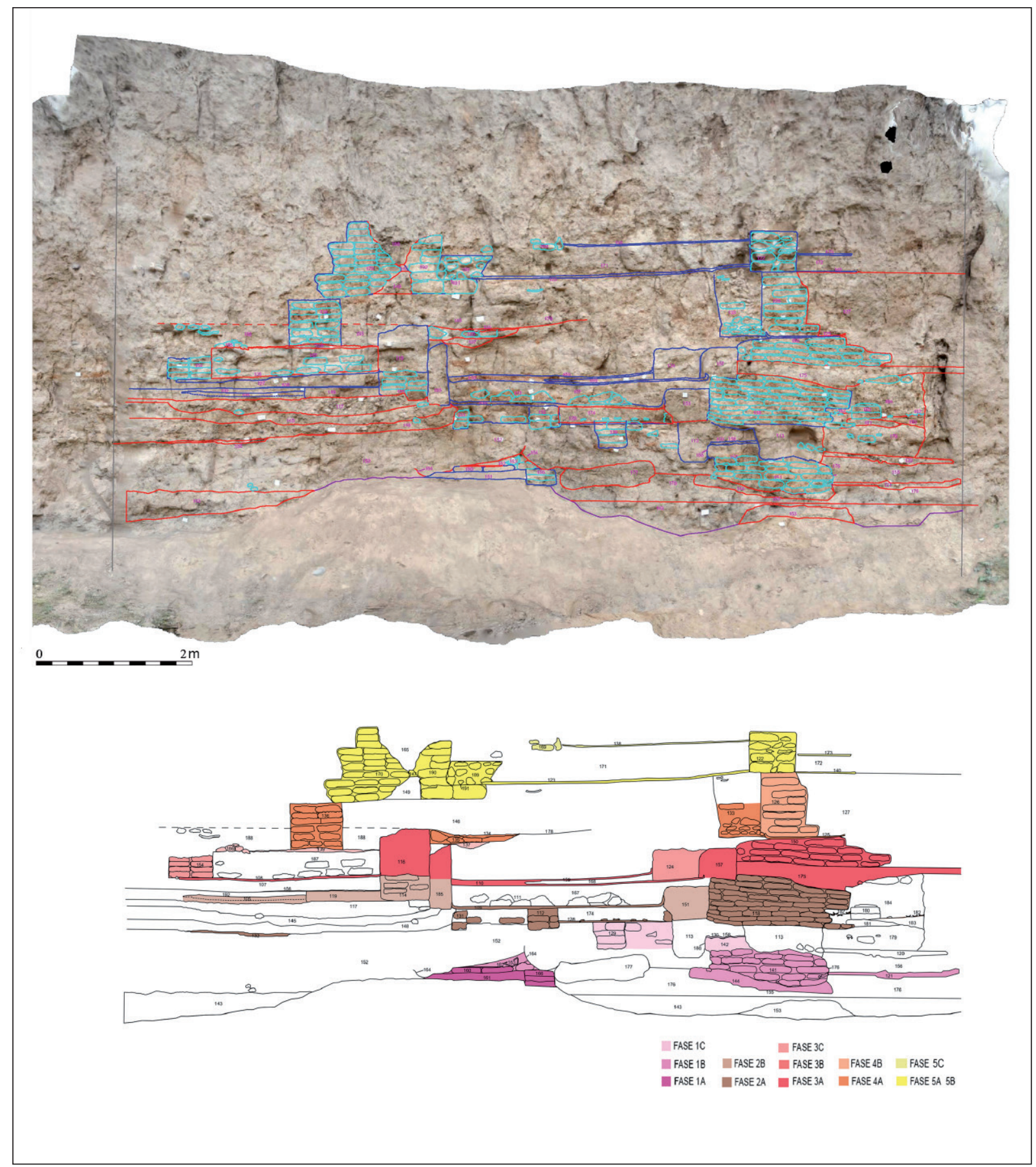

Figura 9. Ortofotografía y dibujo interpretativo del perfil obtenido en el sector 1.

correspondientes a un recipiente de cocina y otro de almacenamiento; tres paredes de ánfora de producción local/regional y tipología indeterminada; y un fragmento también atípico de cerámica a torno común perteneciente a un recipiente de gran tamaño (urna o tinaja).
A partir de aquí se suceden una serie de estructuras constructivas que corresponden a lo que hemos denominado Fase 1 (13,36-13,99 m s.n.m.). La primera de ellas (Fase 1A) comprende dos muros que parecen trabarse en ángulo recto, uno en sentido E-O (UE-166) 
y otro con una orientación aproximada N-S (UE160/161). Están construidos con ladrillos de adobe colocados aparentemente a tizón, al menos en el caso del muro UE-166, con una anchura de unos $37 \mathrm{~cm}$ y una altura documentada de $21 \mathrm{~cm}$ Ninguno se llegó a limpiar por completo ya que ambos se proyectaban también fuera del perfil. El abandono de esta estructura coincide con un depósito compuesto por limos y arcillas que se forma junto al muro UE-166 y se extiende hacia el norte del perfil (UE-176). Sobre él se levanta una segunda estructura (Fase 1B). Se trata de un muro de adobes (UE-141) de unos $40 \mathrm{~cm}$ de longitud y sentido $\mathrm{N}-\mathrm{S}$ sobre un relleno de cimentación de arcilla compactada (UE-155/144), donde se pudo registrar el borde de una olla de cocina modelada a torno y tres fragmentos atípicos a mano, probablemente de almacenamiento (fig. 10). El muro presenta unas dimensiones de 1,50 m de largo por $50 \mathrm{~cm}$ de altura y estaría asociado a un pavimento de guijarros y pequeños cantos (UE-121) de unos $10 \mathrm{~cm}$ de espesor y una longitud de 1,66 m. Al mismo tiempo, parece mantenerse un uso secundario al otro lado de esta estructura, directamente sobre los restos de la fase anterior, donde encontramos un nivel de ceniza muy parcialmente conservado con restos de fauna y cerámica (UE-162). Se trata del fondo de otra olla de cocina a torno de base plana y dos fragmentos de cerámica a torno común, uno de ellos con las características líneas o filetes rojizos y negros de las producciones más antiguas (fig. 10). La amortización de estos niveles se realiza mediante una serie de vertidos de arcillas de similar composición y textura difíciles de diferenciar (UE-152), que sirvieron de base a las estructuras de la Fase 2. No obstante, en la parte norte del perfil aún encontramos un expediente constructivo intermedio que hemos definido como Fase 1C. Consiste en una serie de elementos sin conexión aparente que pudieron corresponder a una estructura muy alterada por los niveles posteriores. Está formada por un posible muro o banco de ladrillos de adobe sin disposición aparente y sentido N-S, de $1 \mathrm{~m}$ de longitud y $35 \mathrm{~cm}$ de alzado conservado (UE-129), y un pavimento de arcilla roja compactada y cal (UE-130) de 1 a $2 \mathrm{~cm}$ de espesor, sobre el que se sitúa una fina capa de ceniza y restos de carbón (UE-158). El pavimento presenta una superficie muy irregular y solo conserva $50 \mathrm{~cm}$ de longitud, ya que está muy afectado por la interfaz negativa UE-186, que pudo servir de zanja de cimentación de la siguiente estructura. Por último, al otro lado del muro UE-141 y sobre su depósito de amortización UE156 , se sitúa un nuevo nivel de gravas y cantos rodados (UE-120), de sección lenticular y algo más potente que el anterior, alcanzando los $10 \mathrm{~cm}$ de espesor en su parte central. Parece conformar un nivel de circulación exterior o un espacio abierto, que hemos vinculado por cota a esta Fase 1C, aunque no tiene conexión aparente con ninguna estructura.

La Fase 2 (14,17-14,39 m s.n.m.) está relacionada con una remodelación general del sector a partir de una serie de unidades negativas y deposicionales que sirvieron para nivelar el terreno y cimentar las siguientes estructuras. La inaugura una primera construcción (Fase 2A) formada por un muro masivo de ladrillos de adobe de entre 35 y $40 \mathrm{~cm}$ de largo, dispuestos casi todos a soga y con llagas horizontales de 2-2,5 cm de ancho aproximado (UE-118). Su conservación es excepcional si lo comparamos con los documentados en este y otros sectores del yacimiento, con hasta 8 hiladas de alzado $(65 \mathrm{~cm})$ y un recorrido de $1,80 \mathrm{~m}$ de longitud. Sigue una orientación N-S, paralela a la del muro UE144/141, sobre el cual se sitúa. Estaría asociado a un nivel de uso UE-182, que aparece dividido en dos por un banco o poyo de $37 \mathrm{~cm}$ de ancho y 19 de altura, formado por dos hiladas de ladrillos de adobe dispuestos a tizón y una pieza de menores dimensiones y forma planoconvexa situada en su parte superior (UE-180). Este muro parece relacionarse también con otra estructura formada por las UUEE-131, 112 y 128, de las que está separado por un banco correspondiente a una refacción posterior (UE-151). La primera parece ser un muro o banco, de $1,37 \mathrm{~m}$ de longitud y $27 \mathrm{~cm}$ de alzado conservado, construido con ladrillos de adobe dispuestos aparentemente a soga y llagas de 1,5 cm de ancho. La segunda es un nivel de uso sin pavimento alguno formado por una acumulación de ceniza, carbones, cantos y cerámica, de unos $2 \mathrm{~cm}$ de espesor y 1,45 m de longitud. Estas estructuras sufren una refacción marcada por la anulación de este último ámbito y la construcción de dos estancias anejas a la formada por el muro UE118, que aún se mantiene en uso (Fase 2B). Se inician con los rellenos UUEE-148, 145, 117 y 174, que elevan y homogeneizan la cota de ocupación. Sobre ellos se dispone una primera estancia que se asocia al muro UE-118 mediante un banco de adobe o tapial dispuesto perpendicularmente a este con una orientación E-O (UE-151). Cuenta con unas dimensiones de $58 \mathrm{~cm}$ de ancho y $42 \mathrm{~cm}$ de alzado, incluyendo su cimentación, ya que en realidad solo sobresale unos $22 \mathrm{~cm}$ de la cota de uso. Se cierra con un tabique de $27 \mathrm{~cm}$ de ancho y 82 $\mathrm{cm}$ de alzado conservado construido probablemente en tapial, ya que no se aprecian los ladrillos de adobe en su sección. Entre ambos se coloca un pavimento de arcilla apisonada y cal, de $4 \mathrm{~cm}$ de espesor y una longitud de 


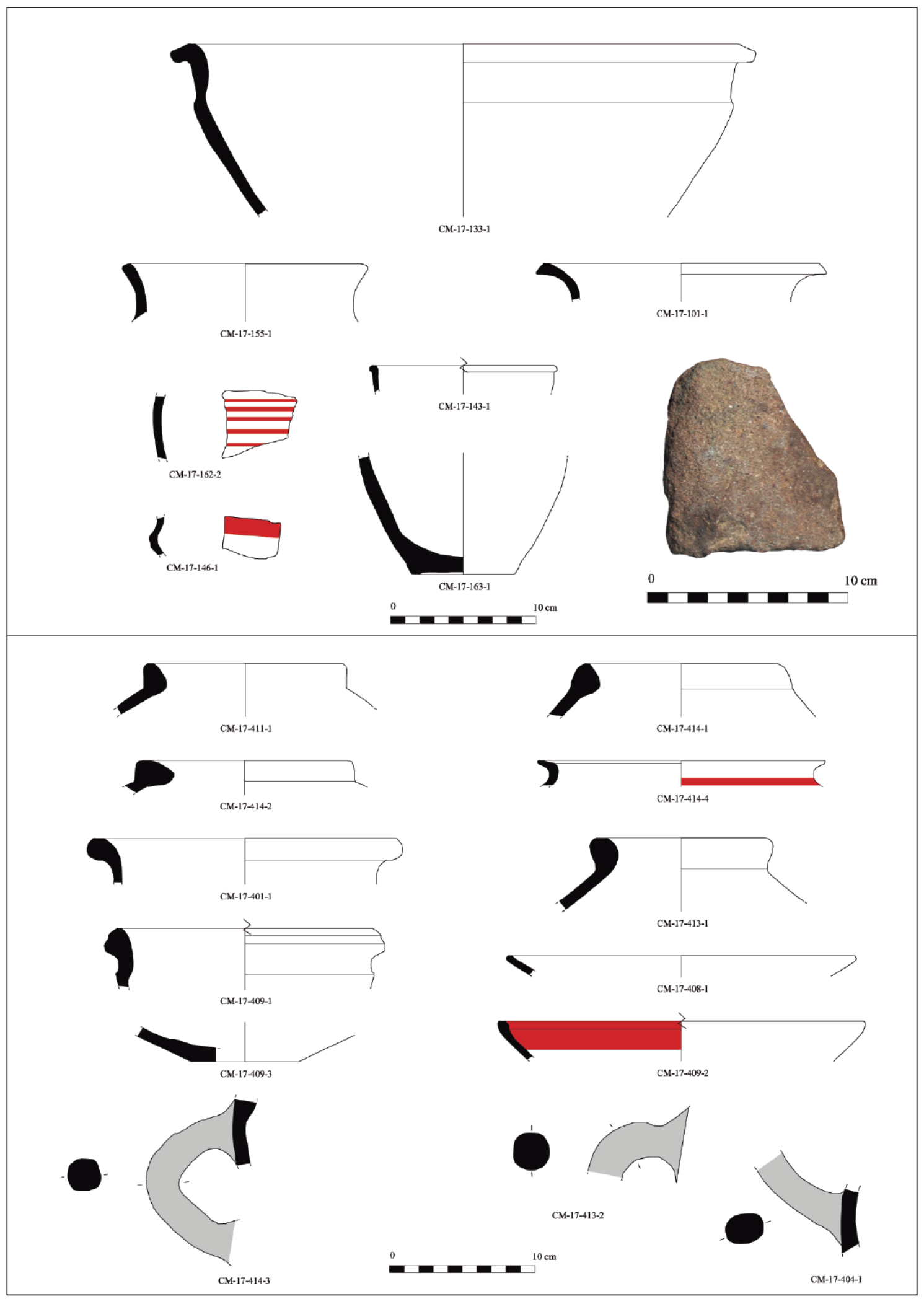

Figura 10. Materiales procedentes de las secuencias obtenidas en los sectores 1 y 4 . 
2,70 m, adosándose a los mismos mediante un revoco cóncavo de media caña (UE-109). Al S encontramos una segunda estancia que se adosa al tabique UE-185. Está formada por un muro de ladrillos de adobe dispuestos aparentemente a soga y tizón, de $65 \mathrm{~cm}$ de ancho y un alzado de $35 \mathrm{~cm}$, con llagas de $1,5 \mathrm{~cm}$ y una orientación aproximada E-O. A él se asocia un pavimento de arcilla roja apisonada y cal de unos $5 \mathrm{~cm}$ de espesor (UE-105). Sin embargo, este fue anulado posteriormente por una plataforma o zócalo de adobe, de $1 \mathrm{~m}$ de largo por $13 \mathrm{~cm}$ de anchura (UE-119/192), que se adosa al muro UE-114 y sirve de asiento a un nuevo pavimento de arcilla roja apisonada y cal: la UE-106. $\mathrm{Su}$ espesor, apenas medio centímetro, indica que este último nivel de ocupación debió ser breve en relación con el anterior. En ambos casos, la extensión de los pavimentos $(2,80 \mathrm{~m}$ de longitud, continuando más allá de los límites del perfil) sugiere que nos encontramos ante una estancia de grandes dimensiones, como mínimo del mismo tamaño que la que se le adosa hacia el S.

A esta fase se superpone una nueva serie de estructuras con la misma disposición y orientación general, la Fase 3 (14,64-15,20 m s.n.m.). Previamente, las tres unidades de habitación documentadas fueron anuladas por sendos depósitos de nivelación que contribuyeron de nuevo a homogenizar la cota de uso: UUEE-184, 111/167 y 107. La primera estructura documentada (Fase 3A) está formada por un muro que se superpone directamente sobre el paramento UE-118, constituido por un zócalo de arcilla muy compacto de unos $28 \mathrm{~cm}$ de espesor (UE-175) y un alzado de ladrillos de adobe dispuestos a soga, con llagas de 1,5 cm (UE-150). Al igual que el anterior, mantiene una orientación N-S, con una altura de $35 \mathrm{~cm}$ y una longitud conservada de $1,94 \mathrm{~m}$. Al S se le adosa de nuevo un banco de adobe o tapial (UE-157). Presenta orientación y dimensiones similares a la UE-151 (47 cm de ancho por $39 \mathrm{~cm}$ de altura) y conforma también una unidad de habitación con el muro UE-185, que aún continúa en uso. Entre ambos se dispone otro pavimento de arcilla apisonada y cal de entre 8 y $10 \mathrm{~cm}$ de espesor y 2,57 m de longitud, con los extremos en media caña (UE-110). Esta estructura coincide al otro lado del muro UE-185 con una refacción de la habitación anterior mediante el recrecido del muro UE-114, probablemente en tapial, y un nuevo suelo de arcilla apisonada y cal (UE-108), de 2-3 cm de espesor y una longitud conservada de $2,57 \mathrm{~m}$. Del interior del tapial se pudo extraer un fragmento de ánfora y otro de cerámica a torno común de tipología indeterminada, pero encuadrables en el Hierro II. Hacia el S de esta estancia se levanta un nuevo muro (UE-154) que parece pertenecer a un segundo momento de ocupación (Fase $3 \mathrm{~B}$ ) y que amortiza parcialmente el pavimento UE-108. Esta construido con ladrillos de adobe aparejados a soga, con $56 \mathrm{~cm}$ de ancho por casi $30 \mathrm{~cm}$ de altura conservada y una orientación E-O, que reduce el tamaño de la habitación a 2,15 m de longitud. Esta subfase la marca realmente la reparación de la estancia contigua mediante la construcción de otro banco, paralelo al UE-157 y levantado directamente sobre el pavimento UE-110. Este nuevo banco (UE-124), de materiales y dimensiones parecidas al anterior $(60 \mathrm{~cm}$ de ancho por 40 de altura), sigue manteniendo una relación funcional con el muro UE-185. Entre uno y otro se instala un segundo pavimento de similares características que viene a recrecer el nivel de uso de la estancia entre 4 y $10 \mathrm{~cm}$ (UE-159), adosándose de nuevo mediante un revoco de media caña al banco UE-124. La amortización de esta estructura se realiza, una vez más, con rellenos de arcilla compacta y ladrillos sueltos de adobe procedentes del desmantelamiento de los muros (UE-167). No obstante, aún se detecta un tercer episodio de ocupación sobre estos rellenos (Fase 3C): dos niveles de ceniza, aparentemente coetáneos, situados a ambos lados del muro UE-116 (UUEE-137 y 139). Pudo tratarse de un nivel de uso, de función y duración indeterminada, aunque no aparece asociado a estructura alguna.

La Fase 4 (15,23-15,38 m s.n.m.) es quizá la peor documentada, tanto por la escasa entidad de las construcciones como por las lagunas existentes en la parte central del perfil. No obstante, las estructuras registradas parecen mantener con pocas variaciones la disposición de las precedentes. Es el caso del muro UE-133, que se sitúa justo sobre el muro UE-150 y el banco UE157 , con una orientación análoga a la de este último. Se trata de un paramento de ladrillos de adobe muy mal conservado, de $55 \mathrm{~cm}$ de ancho y unos $78 \mathrm{~cm}$ de alzado, construido sobre una base de dos o tres hiladas de cantos de río de mediano tamaño. De su parte superior, y procedente probablemente de su amortización, se desprendieron dos paredes de ánfora de tipología indeterminada y un borde de lebrillo, una forma muy común que podemos fechar entre los ss. IV y III a.C. (fig. 10). El muro UE-133 se encuentra asociado a un pavimento de arcilla apisonada y cal de $2-3 \mathrm{~cm}$ de ancho y poco más $1 \mathrm{~m}$ de longitud, que se pierde en el límite de la unidad de intervención (UE-125), mientras que en el centro del perfil hallamos otro nivel de uso, relacionado probablemente con la misma estructura, ya que parece reproducir la disposición de las estancias de la Fase 3. Consiste de nuevo en un pavimento de arcilla roja y 
cal parcialmente conservado, del que apenas se ha registrado $1 \mathrm{~m}$ de recorrido (UE-178), asociado a un paquete de ceniza y restos cerámicos de forma lenticular que pudo corresponder a un hogar (UE-134). Al otro lado de estos muros, un nuevo paramento parece cumplir la misma función de reconstrucción de las estructuras precedentes (UE-136), aunque en este caso no se ha podido determinar su nivel de uso. Se asienta directamente sobre el depósito de ceniza UE-139 mediante una zanja de cimentación (UE-115) que atraviesa el relleno de la ocupación anterior (UE-188). Está construido sobre una primera capa de piedras, en este caso de caliza o calcarenita, con un alzado de ladrillos de adobe dispuestos a soga de $65 \mathrm{~cm}$ de ancho, un alzado conservado de $55 \mathrm{~cm}$ y una orientación E-O. En un segundo momento (Fase 4B), se construye directamente sobre el suelo de la estructura anterior (UE-125) un segundo muro bastante potente de ladrillos de adobe aparejados indistintamente a tizón o a soga y tizón, con anchas llagas de arcilla (UE-126). Presenta unos $54 \mathrm{~cm}$ de ancho y una altura conservada de $75 \mathrm{~cm}$, mientras que parece mantener la orientación habitual E-O. Después de esta refacción se produce una nueva reforma general del sector que implica, una vez más, el desmoche de los muros y el relleno de las estructuras con tierra y escombros (UUEE-127 y 146). Entre los materiales registrados se pudieron identificar una pared de ánfora de producción local/regional y dos fragmentos de cerámica a torno común, uno de los cuales parece corresponder a un cuenco tulipiforme (fig. 10), una forma relativamente habitual en el s. III a.C. (Ferrer y García 2008: 208).

La Fase 5 (15,93-16,49 m s.n.m.) es la última registrada en este perfil y está marcada por la introducción de algunas novedades constructivas, como es la aparición del cimiento-zócalo de mampuestos careados, que viene a sustituir a la hilada de cantos de río que solía utilizarse en las fases anteriores, aunque estos no llegarán a desaparecer por completo. El muro que mejor ejemplifica este proceso es el UE-122. Está construido con bloques de piedra caliza de mediano tamaño, careados al exterior y unidos con argamasa de barro y grava. Presenta un alzado conservado de $52 \mathrm{~cm}$ y una anchura de $58 \mathrm{~cm}$, por lo que mantiene las dimensiones medias del resto de las estructuras domésticas documentadas, aunque en este caso parece adoptar una orientación SONE. Al muro se adosan dos pavimentos de similares características, realizados con lechadas de arcilla roja y cal de entre 2 y 3,5 cm de espesor: uno al N (UE-140), cuyo recorrido se pierde en los límites del perfil, y otro al S (UE-123), conformando una estancia de 3,30 m de longitud cerrada por un segundo muro (UE-189), conservado únicamente a nivel de cimiento (UE-191). En ella apareció un fragmento de pared de ánfora de producción local/regional de tipo indeterminado y el extremo de un molino barquiforme realizado en granito, que se encontraba apoyado justo en el contacto entre el pavimento UE-123 y el muro UE-122 (fig. 10). Llama la atención cómo esta estructura (Fase 5B) reproduce a grandes rasgos la disposición y casi el tamaño de las habitaciones que se superponen entre las fases 2B y $3 \mathrm{~B}$. En efecto, al otro lado del muro UE-189 se había construido previamente una estructura que se asentaba directamente sobre el muro UE-136 y el relleno UE-146 (Fase 5A). De ella conservamos la sección de un muro de adobe o tapial (UE-190), al que se adosa el anterior mediante la interfaz UE-191, y el alzado de un segundo paramento que parece cerrar en ángulo recto con aquel (UE-170). De este último solo se conservan escasos centímetros de su espesor original, prácticamente desmantelado por las excavadoras, por lo que a través de las partes más deterioradas se pueden apreciar los niveles de preparación, uso y amortización de una estancia que se extiende hacia el interior del perfil, entre los que destaca un pavimento ancho de arcilla roja y cal (UE-147), del que únicamente han podido documentarse $10 \mathrm{~cm}$ de longitud. El muro UE-190 es una construcción muy compacta de arcilla de unos $40 \mathrm{~cm}$ de ancho por $75 \mathrm{~cm}$ de alzado y orientación E-O o, más probablemente, E-NE. El muro UE-170, por su parte, está realizado con ladrillos de adobe de dimensiones indeterminadas, dispuestos a soga y trabados con arcilla. Conserva una altura máxima de $92 \mathrm{~cm}$ y una orientación aproximada S-N o NNO-SSE. Por último, fue detectado un tercer nivel de ocupación en relación con el muro UE-122 (Fase 5C). Se trata de dos pavimentos de arcilla y cal de apenas $2 \mathrm{~cm}$ de espesor dispuestos respectivamente al $\mathrm{N}$ y al $\mathrm{S}$ del mismo, sobre los depósitos que anularon las estancias anteriores: UUEE-172 y 171. El situado más al N (UE-173) se encuentra a una cota inferior (20 cm aproximadamente) y desconocemos sus dimensiones totales, ya que continúa fuera del área de intervención. El otro pavimento (UE-138) conforma una nueva habitación, más pequeña que la anterior (2,40 $\mathrm{m}$ de longitud), al adosarse a un murete de mampostería caliza de $40 \mathrm{~cm}$ de ancho del que solo se conservan las dos primeras hiladas de piedra (UE-169).

A pesar de la escasez de materiales datantes podemos, a modo de hipótesis, proponer una cronología aproximada para las diferentes fases de ocupación identificadas. La Fase 1, con sus distintos episodios, correspondería al Hierro I, desarrollándose probablemente entre el último cuarto 
del s. VII y finales del VI a.C. La reforma que inaugura la Fase 2 tendría lugar a principios del s. V a.C., mientras su uso se extendería a lo largo de esta centuria. Las construcciones pertenecientes a la Fase 3 podría fecharse grosso modo de finales del s. V a la primera mitad del IV a.C. y la Fase 4 en su segunda mitad, aunque los límites cronológicos son poco claros. En todo caso, los materiales correspondientes a la amortización de la estructura formada por las UUEE-136, 133 y 134, son compatibles con una fase avanzada de esta centuria. Por último, la Fase V se extendería a lo largo del s. III a.C. hasta su último tercio, coincidiendo con la introducción de los zócalos de mampuestos en los muros de tierra, que se produce en un momento avanzado de esta centuria.

\subsection{Sector 4}

Este sector es el que ha ofrecido resultados más limitados debido tanto a las condiciones de trabajo del lugar, con la cota superficial del cerro más baja, taludes más potentes y perfiles peor conservados, como a la complejidad de la secuencia, con elementos poco elocuentes y de escasa continuidad, muy alterados por la acción de las excavadoras y del arado, en la superficie. Debido a ello actuación se tuvo que centrar en los niveles superiores, a una cota inferior de 14,50 y una cota superior de $16,51 \mathrm{~m}$ s.n.m., alcanzando una potencia de 2,01 m y una longitud máxima de 4,70 m (fig. 11).

El primer nivel de ocupación registrado, que denominamos Fase 1 (14,49-14,85 m s.n.m.), corresponde a un depósito de ceniza de forma lenticular, de apenas $58 \mathrm{~cm}$ de diámetro (UE-412), relleno con caracoles con evidencias de haber sido manipulados para su consumo, ya que presentan orificios en sus caparazones, de forma muy similar a los documentados en los niveles iniciales de las excavaciones en Pajar de Arti1lo, Itálica (Luzón 1973: 13, lám. XXVIII-A). Parece tratarse de un hogar o cocina asociado a un posible pavimento (UE-404), solo parcialmente conservado en la parte central del perfil, compuesto por arcilla suelta, ceniza y abundantes restos cerámicos. Entre ellos se pudieron registrar un asa y varias paredes de ánforas de producción local/regional, así como otros fragmentos de recipientes a torno, especialmente algunos pertenecientes a grandes vasos globulares pintados (fig. 10). A partir de aquí se sucede una serie de depósitos de relleno y niveles de uso más propios de un espacio abierto que del interior de una vivienda, ya que las superficies están formadas simplemente por una acumulación de cantos rodados y tierra apisonada mezclada con cerámicas, ceniza y detritus (UUEE-419 y 420). En sus respectivos preparados (UUEE-407 y 411) se registró un fragmento de cerámica gris orientalizante, probablemente un cuenco o plato, y el borde de un ánfora arcaica T.10.1.2.1 (fig. 10), tratándose posiblemente de materiales residuales.

La Fase 2 (14,85-15,24 m s.n.m.) se inaugura con un muro de adobe que solo se conserva, muy alterado, en la parte central del perfil (UE-406). Está aparejado con ladrillos de unos $40 \mathrm{~cm}$ de longitud dispuestos aparentemente a soga. La parte superior forma una línea continua y más homogénea de arcilla color rojizo que pudo corresponder a un alzado de tapial posteriormente desmantelado para la siguiente construcción. El muro presenta una altura de $20-25 \mathrm{~cm}$ en la parte mejor conservada, donde se pudieron registrar hasta tres hiladas de adobe, y un recorrido mínimo de $3 \mathrm{~m}$ en dirección SE-NO. Resulta difícil precisar los límites orientales del muro y las relaciones estratigráficas con el resto de las unidades. No obstante, es posible que el depósito que encontramos a la misma cota al este del corte (UE-408) funcionara como un nivel de amortización/nivelación destinado a servir de base a la siguiente fase. Se trata de un relleno de arcilla compactada y restos de adobe, procedentes probablemente del mismo muro, con algunos materiales cerámicos: un borde de cuenco realizado a torno y varios fragmentos de ánfora pertenecientes a un mismo individuo (fig. 10). El resultado es una superficie horizontal donde se dispone el siguiente expediente constructivo (Fase 2B), un nivel de cantos rodados de mediano/gran tamaño y algunos fragmentos cerámicos (UE-402) que se extiende a lo largo de 3,5 m en sentido E-O o SE-NO, apoyándose directamente sobre el muro UE-406. Por el tamaño y disposición de los cantos podría interpretarse como la cimentación de otro muro de adobe, si no fuera porque sobre el mismo se sitúa un nivel de uso (UE-403) constituido simplemente por una capa de tierra arcillosa, endurecida en su superficie y con restos de ceniza. Contenía restos muy fragmentados de cerámica, especialmente ánforas (una de ellas de producción arcaica) y recipientes de almacenamiento realizados a torno. Sobre este se deposita una capa de tierra suelta limosa, con abundantes materiales, que podría corresponder al nivel de abandono de esta fase, previo a su amortización (UE-409). Entre ellos destacan los bordes de un cuenco y de un lebrillo, decorados ambos con pintura roja, y abundantes fragmentos de ánforas y grandes vasos de almacenamiento a torno pintados (fig. 10). La amortización de esta subfase se llevó a cabo mediante una serie de depósitos yuxtapuestos de 25 a 45 $\mathrm{cm}$ de espesor, cuyos límites y relaciones estratigráficas 


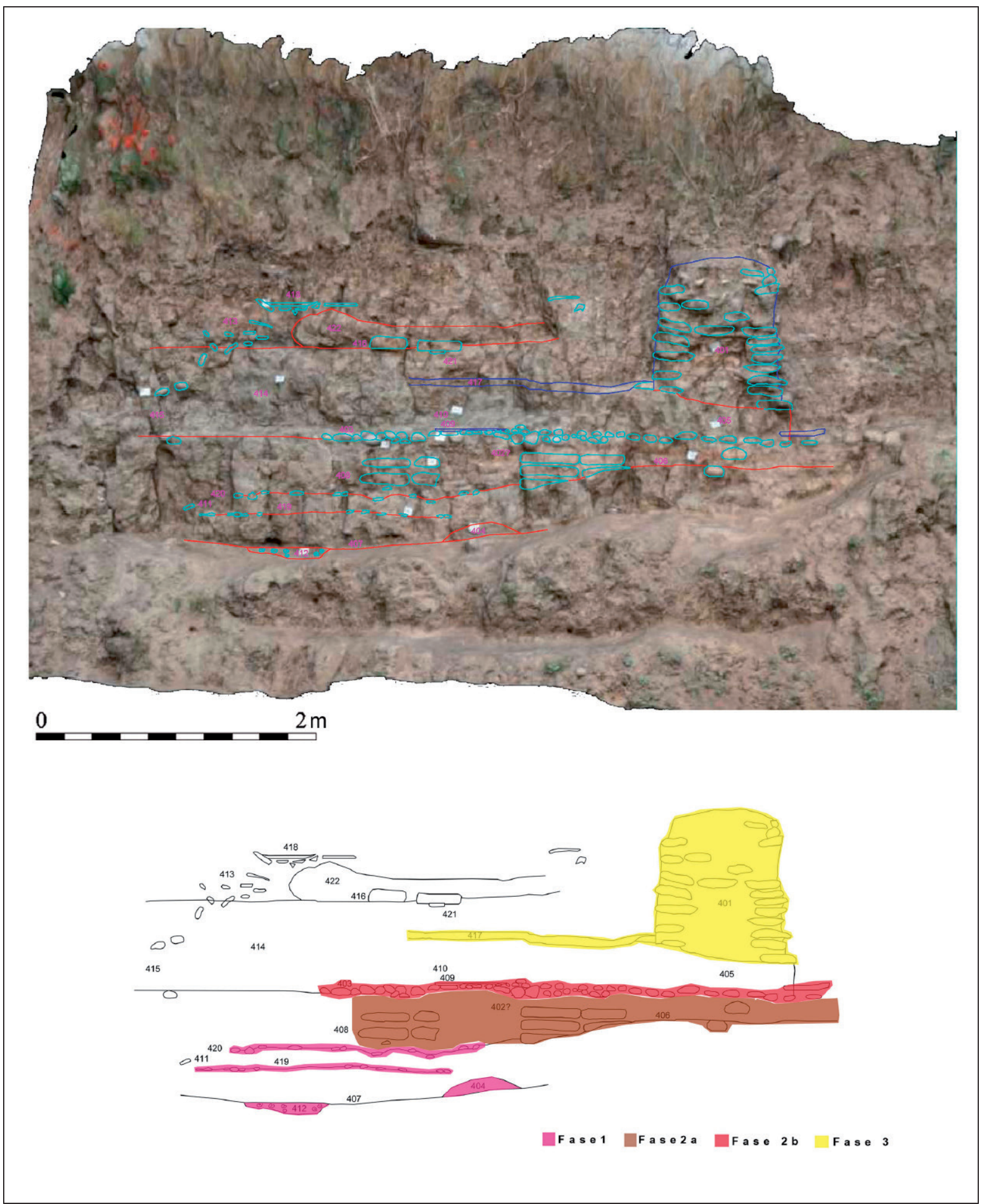

Figura 11. Ortofotografía y dibujo interpretativo del perfil obtenido en el sector 4.

ISSN: 1133-4525 ISSN-e: 2255-3924 
no son suficientemente claros (UUEE-405, 410, 414 y 415), aunque pueden diferenciarse grosso modo a partir de la matriz y el material contenido, un elenco abundante y variado de cerámicas de cronología turdetana. De la UE-410 se extrajeron varias paredes de ánforas de distintas procedencias correspondientes, al menos, a 11 individuos, mientras que la UE-414 ofreció un asa y dos bordes de ánfora, una indeterminada y otra perteneciente a una variante antigua del tipo Mañá-Pascual A4, un borde de urna pintada de pequeño tamaño, además de fragmentos atípicos de ánforas y de grandes recipientes a torno de almacenamiento, algunos con decoración pintada (fig. 10).

Sobre estos depósitos se cimentó la siguiente estructura, correspondiente a la Fase 3 (15,59-15,79 m s.n.m.). Se trata de un zócalo de mampostería careada realizado con lajas de caliza de mediano tamaño, dispuestas horizontalmente y trabadas con tierra (UE401), donde aparecen algunos restos cerámicos, entre ellos un borde de recipiente de cocina a torno (fig. 10). Presenta unos $90 \mathrm{~cm}$ de ancho por poco más de $1 \mathrm{~m}$ de alzado conservado, con una orientación N-S, y se encuentra asociado a un nivel de uso de similares características que la UE-403: una superficie de tierra arcillosa endurecida, con restos de ceniza y cerámica incrustada (UE-417). No ha sido posible calcular sus dimensiones, ya que solo aparece adosada al muro y en algunos puntos del centro del perfil, perdiéndose hacia el E, quizá alterada por el siguiente nivel de ocupación. Este se sitúa en la mitad oriental como una capa de ceniza de 1,7 $\mathrm{m}$ de longitud mínima y entre 4-5 cm de espesor (UE416), dispuesta sobre un pequeño depósito de arcilla y cal bastante compactado (UE-421), aunque no parece guardar relación estratigráfica con el muro UE-401. Con todo, el final de esta fase, la última con estructuras conservadas, viene marcado por un nivel de derrumbe sobre la UE-416, donde encontramos ladrillos de adobe procedentes de algún muro próximo, así como abundantes restos cerámicos y algunos cantos, mezclados con arcilla rojiza (UE-422). Asociadas a este nivel se pueden individualizar, además, dos concentraciones significativas: la UE-418 y la UE-413, que proporcionó el borde y un asa de ánfora de producción local/regional perteneciente al tipo Pellicer B/C (fig. 10).

Este sector sí ofreció suficientes materiales como para establecer una secuencia cronológica aproximada, aunque teniendo en cuenta la cota a la que se sitúa la unidad de intervención, solo se han podido registrar muy parcialmente algunas fases de ocupación correspondientes a momentos avanzados de la Edad del Hierro. Si nos atenemos a la posición relativa de la Fase 1 con respecto a las secuencias obtenidas en otros puntos del yacimiento, podríamos fechar esta ocupación en la primera mitad del s. IV a.C., lo que no desentona con los materiales hallados en la UE-404. La Fase 2 se centraría entre mediados de esta centuria e inicios de la siguiente. Aunque los abundantes restos anfóricos son poco elocuentes, tanto la posición estratigráfica de estos niveles como las producciones comunes identificadas en los mismos apuntan a esta cronología. Por último, la Fase 3 correspondería grosso modo al s. III a.C. Hay pocos materiales asociados al uso y amortización de esta estructura, aunque la entidad del muro UE-401 y las técnicas constructivas empleadas en el mismo solo suelen documentarse, como se verá, a esta cota y a partir de esta fecha.

\subsection{Sector 5}

Este sector ofrecía a priori una sucesión bastante elocuente y regular de pavimentos y algunas estructuras de adobe. La unidad de intervención se estableció al $\mathrm{S}$ del mismo, entre las cotas 12,78 y 15,53 m s.n.m. (2,80 m de potencia), abarcando una longitud máxima de 8,80 m (fig. 12). No obstante, a pesar de la claridad que presenta gran parte de la secuencia, la escasez de materiales recuperados -la mayor parte en el talud-y su poca entidad ha dificultado la adscripción cronológica de los distintos niveles.

La Fase 1 (13,05-13,60 m s.n.m.) está formada por dos posibles construcciones. La primera (Fase 1A) se asienta sobre una serie de depósitos de relleno (UUEE530 y 551), el último de los cuales pudo servir de primer nivel de uso de esta estructura. Está constituida por un muro de adobe o tapial (UE-536) y posible orientación N-S, al que se asocia un segundo nivel de uso, un posible pavimento de arcilla roja y cal (UE-535), que a su vez se asienta sobre un nivel de recrecimiento formado por las UUEE-529 y 532. No obstante, la conservación de estos niveles es muy deficiente para poder avanzar sobre el carácter de esta estructura. El único material recuperado de esta fase es un fragmento de pared de ánfora de procedencia malagueña hallado en la UE-529 y fechable de forma imprecisa en el Hierro I. La segunda (Fase 1B) está formada por un muro de ladrillos de adobe aparejados a tizón de unos $45 \mathrm{~cm}$ de longitud y una altura conservada de $55 \mathrm{~cm}$ (UE-534), que se dispone de forma perpendicular sobre el primero (UE-536). Se encuentra asociado a un depósito (UE520) que, además de amortizar la estructura anterior, pudo haber servido de preparación para un suelo hoy perdido, así como a una compleja serie de vertidos que 


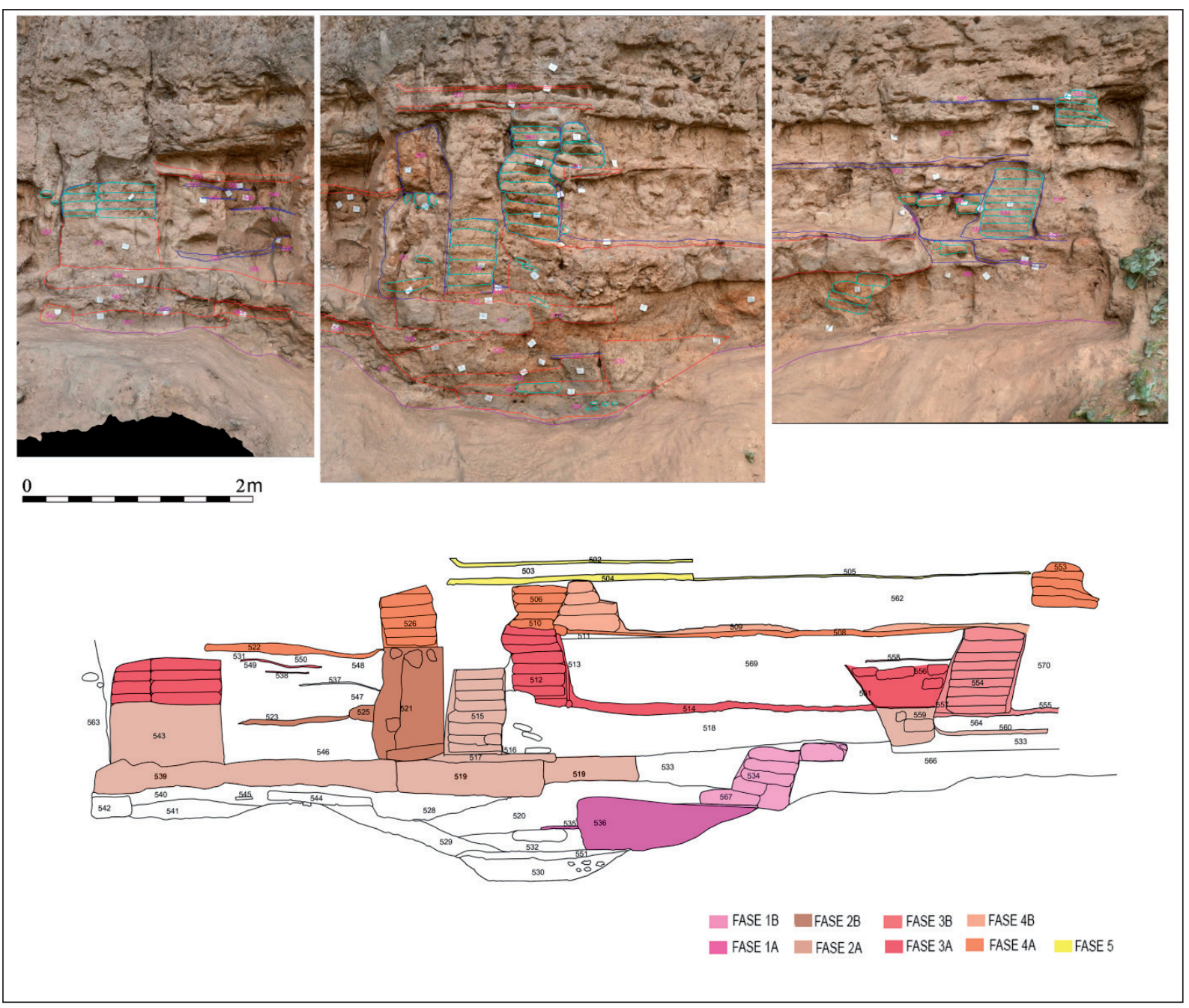

Figura 12. Ortofotografía y dibujo interpretativo del perfil obtenido en el sector 5.

se extienden hacia el N. La conforman varios niveles de arcilla compacta muy irregulares (UUEE-541, 542, 545) sobre los que se superponen capas de cantos rodados de forma lenticular (UUEE-540 y 528), que pudieron haber servido de superficie de circulación de un espacio abierto o una calle. En ellos, y especialmente en la UE-540, se documentaron abundantes restos cerámicos, sobre todo fragmentos atípicos de ánforas y recipientes de almacenamiento realizados a torno, algunos pintados. Los niveles de destrucción de esta segunda estructura se limitan al relleno formado por la posible caída del muro UE-534 hacia el S (UE-566), ya que el resto está muy alterado por la preparación de la siguiente fase constructiva.

En efecto, la Fase 2 (13,88-14,19 m s.n.m.) está precedida por una profunda remodelación que implicó la nivelación del terreno mediante depósitos de arcilla y tierra (UE-533) y potentes dados de cimentación de adobe (UUEE-539 y 519) de unos $30 \mathrm{~cm}$ de espesor medio, que sirvieron de base a las nuevas estructuras. La cronología aproximada de esta reforma vendría marcada por los materiales registrados en los rellenos, en su mayoría restos muy fragmentados de ánforas y recipientes de almacenamiento realizados a torno, cuyas pastas y decoraciones se encuadran ya en el Hierro II. La primera serie de estas estructuras (Fase 2A) está formada por el muro UE-517/515, asociado al pavimento UE-516; el muro UE-559, asociado al pavimento UE-560; y el muro UE-543, que no aparece relacionado con ningún nivel de uso. En todos los casos se trata de muros de ladrillos de adobe de $40-50 \mathrm{~cm}$ de módulo, unidos con argamasa del mismo material, 
dejando llagas de unos $2 \mathrm{~cm}$. Los dos primeros fueron aparejados a tizón, mientras que el muro UE-543 presenta dos filas de ladrillos, una a soga y otra a tizón, lo que le otorga un ancho $90 \mathrm{~cm}$ aprox. Los pavimentos (UUEE-516 y 560), por su parte, son de arcilla roja apisonada y cal, de unos 2-3 cm de espesor. El muro UE$517 / 515$, de $70 \mathrm{~cm}$ de alzado conservado, y el UE-559, de apenas $32 \mathrm{~cm}$, parecen conformar una amplia habitación de 3,30 m aproximados de ancho o largo, mientras que a partir de este último se abre otra en dirección $\mathrm{S}$, cuyo cierre no sido documentado. Adosado al muro UE-517/515 se levantó un segundo paramento de similares materiales, técnicas y dimensiones (UE-521/525), aunque mucho más deteriorado por la acción de las palas mecánicas (Fase 2B), como se observa en la profunda mordida del perfil. Arranca del mismo nivel de cimentación UE-519, aunque parece estar asociado al pavimento UE-523, algo más ancho y a una cota superior con respecto a los anteriores, descansando sobre el relleno UE-546. Observamos que la distancia de aquel con respecto al muro UE-543 es muy reducida $(1,30 \mathrm{~m})$, por lo que no podemos descartar la posibilidad de que se trate de una calle, o más probablemente un espacio de circulación interior, si tenemos en cuenta la secuencia de depósitos y pavimentos que se suceden regularmente en la siguiente fase. El final de la Fase 2 viene marcado por un desmantelamiento parcial e intencionado de los muros precedentes para la posterior reconstrucción de estas mismas estructuras. Los espacios delimitados por ellos fueron rellenados con depósitos de amortización/nivelación compuestos por limo, arcilla, y ceniza (UUEE-546 y 564), así como restos de ladrillos de adobe (UE-518), que se concentran sobre todo al pie del muro UE-517/515.

La Fase 3 (14,24-14,68 m s.n.m.) la conforman una serie de estructuras que suceden claramente a las anteriores, ya que no solo mantienen la misma orientación y dimensiones, sino que se superponen y adosan a los muros previos. También reproducen las mismas técnicas constructivas: ladrillos de adobe de unos $50 \mathrm{~cm}$ de módulo dispuestos a tizón, unidos con argamasa de arcilla de $2 \mathrm{~cm}$ de ancho, y pavimentos de arcilla roja apisonada y cal que, en este caso, suelen superar los $5 \mathrm{~cm}$ de espesor. La primera (Fase 3A) está constituida por los muros UUEE-512 y 556, de 70 y $35 \mathrm{~cm}$ de alzado conservado respectivamente, y revestidos en ambos casos con un espeso enlucido de cal. Entre ellos encontramos un potente pavimento de 2,60 m de ancho o largo y unos $10 \mathrm{~cm}$ de espesor (UE-514), fruto de constantes reparaciones, ya que esta habitación parece haberse mantenido en uso durante toda la fase ocupacional. Hacia el S, otro pavimento de $6 \mathrm{~cm}$ de espesor (UE-555) se adosa al muro UE-556, delimitando una estancia que se pierde en el perfil. Por su parte, en el extremo N, el muro UE-543 parece recrecerse con los mismos materiales y técnicas, conservando en esta fase un alzado de $40 \mathrm{~cm}$ (UE-524). Sin embargo, no han podido registrarse niveles de uso asociados más allá de una secuencia de pavimentos de escaso espesor (UUEE-537, 538 y 531) y sus respectivos niveles de amortización/preparación (UUEE-548, 549, 550), que quedan aislados entre este y el muro UE-521/525 debido al deterioro de esta parte del perfil. Ellos pueden pertenecer, como se ha dicho arriba, a un espacio de circulación interior reparado en sucesivas ocasiones, al menos tres en esta fase, hasta su posterior amortización. La siguiente estructura (Fase 3B) corresponde a reparaciones realizadas sobre las estancias formadas por los muros UUEE-512 y 556. En un momento determinado, el muro UE-556 se queda obsoleto y se construye un nuevo paramento (UE-554) de similares características y orientación, aunque un poco más ancho, asentándose directamente sobre el pavimento UE-555. De él se conservan unos 75 $\mathrm{cm}$ de alzado, al igual que del muro UE 512, que continúa en funcionamiento durante esta subfase. La base del muro UE-557 parece mantenerse, no obstante, como un banco adosado revestido de capas de arcilla roja apisonada y cal similares a los suelos conservados, aunque más estrechos (UE-558). Al otro lado del muro UE-554, el pavimento UE-555 se recrece para adosarse al mismo mediante la habitual solución de media caña, continuando igualmente en dirección $\mathrm{S}$ hasta perderse en el perfil. La amortización de esta estructura viene dada por los depósitos de relleno UUEE-569 y 556, mientras que en el extremo $\mathrm{N}$ del perfil el final de esta fase de ocupación corresponde probablemente al depósito UE-550, que sirve de preparación al siguiente nivel de uso. Los primeros están formados por restos constructivos procedentes del desmantelamiento de las estructuras previas, que se concentran sobre todo al pie de los muros y van disminuyendo en el centro de la habitación, como puede apreciarse en las líneas de enlucido que aún se mantienen adheridas a los ladrillos de adobe, sobre los que se vierten tongadas de tierra compactada.

Sobre estos rellenos se dispone la Fase 4 (14,7214,98 m s.n.m.), constituida de nuevo por dos estructuras, una al $\mathrm{S}$ más completa y otra al $\mathrm{N}$ del perfil, solo conservada muy parcialmente. La primera (Fase 4A) conforma una habitación que se superpone directamente sobre la anterior, previa nivelación (UE-511), aunque presenta mayores dimensiones, alcanzando prácticamente los $4 \mathrm{~m}$ de longitud. Está delimitada por 
el muro UE-510/506, de unos $40 \mathrm{~cm}$ de alzado conservado, que se asienta justo sobre el muro UE-512, y por el muro UE-553, de unos $38 \mathrm{~cm}$ de alzado. El pavimento (UE-508) es similar al de las estructuras previas, aunque no se adosa al muro UE-553, sino que continúa por debajo, lo que lleva a pensar que este funcionara más bien como un tabique de compartimentación interna y no como un muro de cierre. Sobre el pavimento, y relacionado con su última fase de uso, aparecieron algunos fragmentos cerámicos de cronología turdetana: dos paredes de ánforas, una de probable procedencia malagueña y otra de producción local/regional, varios fragmentos de cerámica a torno pintada y restos de escoria de cobre. Posteriormente, al muro UE-510/506 se adosa un banco del mismo material (Fase 4B), de unos $50 \mathrm{~cm}$ de ancho y altura indeterminada, pues fue descabezado en la Fase 5 (UE-507). Este banco se instala también directamente sobre el pavimento UE-508, aunque en esta ocasión se repara para adosarse a aquel formando un bocel de media caña (UE-509). Sobre él también se documentaron algunos restos cerámicos, aunque más escasos, representados sobre todo por un borde de cuenco común a torno (fig. 13). La segunda estructura (Fase 4A) se sitúa al $\mathrm{N}$ del perfil y está compuesta de nuevo por un muro y un pavimento adosado. El muro está construido con una primera hilada de cantos rodados de medio tamaño (UE-527) y un alzado de ladrillos de adobe (UE-526) de $46 \mathrm{~cm}$ de módulo dispuestos a tizón, con una altura de $51 \mathrm{~cm}$ en la parte mejor conservada. Se sitúa sobre el muro UE-521/525 de la Fase 2, ya completamente amortizado, siguiendo la misma orientación. El suelo, por su parte, presenta las mismas características que los anteriores: capas alternas de arcilla roja apisonada y cal, alcanzando un espesor de unos $9 \mathrm{~cm}$. Aunque solo conserva una longitud de 1,55 m, ambos parecen conformar una habitación que se superpone al posible espacio de tránsito formado entre los muros UE-521 y UE-543/524. En todo caso, el deterioro de esta parte del perfil y las dificultades del trabajo por encima de esa cota desaconsejaron continuar la limpieza y registro en este punto.

Debido a ello, la siguiente fase solo se pudo documentar en la parte central y sur del perfil. La amortización de las estructuras precedentes se realizó siguiendo el mismo procedimiento de desmantelamiento parcial de los muros y el vertido de sus escombros, tierra y otros materiales como relleno (UE-562). No obstante, el muro UE-553 parece haberse mantenido aún visible o incluso en uso, aunque no se ha podido precisar con exactitud su relación con los niveles posteriores. La Fase 5 (15,32-15,53 m s.n.m.) corresponde a una sucesión pavimentos de arcilla de distinta factura y espesor variable (UUEE-505 y 503) y niveles de uso o abandono compuestos por cenizas, carbones y abundante detritus (UUEE-504 y 502). Sobre ellos se sitúa un potente nivel de relleno de tierra arenosa, restos constructivos y cerámicos que se extiende por encima del área de intervención prevista. Este último pudo servir de base a la siguiente fase, correspondiente a un muro de mampostería y cantos rodados que se observa al $\mathrm{N}$ de perfil, fuera del corte, sobre una cota de 16 m s.n.m. y que por motivos de seguridad no llegó a ser registrada.

Aunque el repertorio material aportado por esta unidad de intervención ha sido con diferencia el más reducido de todos los sectores estudiados, tanto la coherencia de la secuencia como sus similitudes con la obtenida en el sector 1 permiten a grandes rasgos proponer una cronología aproximada a las distintas fases. En este sentido, la Fase 1 podría fecharse en el s. VI a.C., como parecen apuntar los materiales asociados a su amortización, que evidencian la transición al Hierro II. La gran remodelación que antecede a la Fase 2 correspondería, como en el sector 1 , a inicios del s. V a.C. y sus distintos episodios constructivos a esta centuria. La Fase 3, por su parte, iría desde finales del s. V a inicios del IV a.C., mientras que la Fase 4 ocuparía el tramo central de este siglo. Los pocos materiales asociados a sus dos niveles de uso sucesivos (UUEE-508 y 509) no desentonan con esta cronología. A partir de aquí se sucederían los niveles pertenecientes a la Fase 5 , que podemos fechar con poca precisión entre finales del s. IV e inicios del III a.C.

\subsection{Sector 7}

En este caso la unidad de intervención se ubicó en el vértice suroccidental de la elevación oriental, en un punto donde la pendiente del talud descendía suavemente facilitando la limpieza del perfil a varios niveles de altura y permitiendo de este modo contar con una lectura más completa de la secuencia. El perfil se dividió, por tanto, en tres tramos dispuestos a distinta cota, entre los 12,53 y los 17,43 m s.n.m (fig. 14), abarcando una potencia acumulada de $4,90 \mathrm{~m}$ y una longitud total de $8,90 \mathrm{~m}$. Sin embargo, aunque el repertorio material aportado por este sector es un poco más amplio, adolece en cambio de niveles constructivos elocuentes, a excepción de la parte superior de la estratigrafía. En su mayoría está formado por una sucesión de superficies de uso, depósitos de ceniza y suelos de tierra apisonada, 


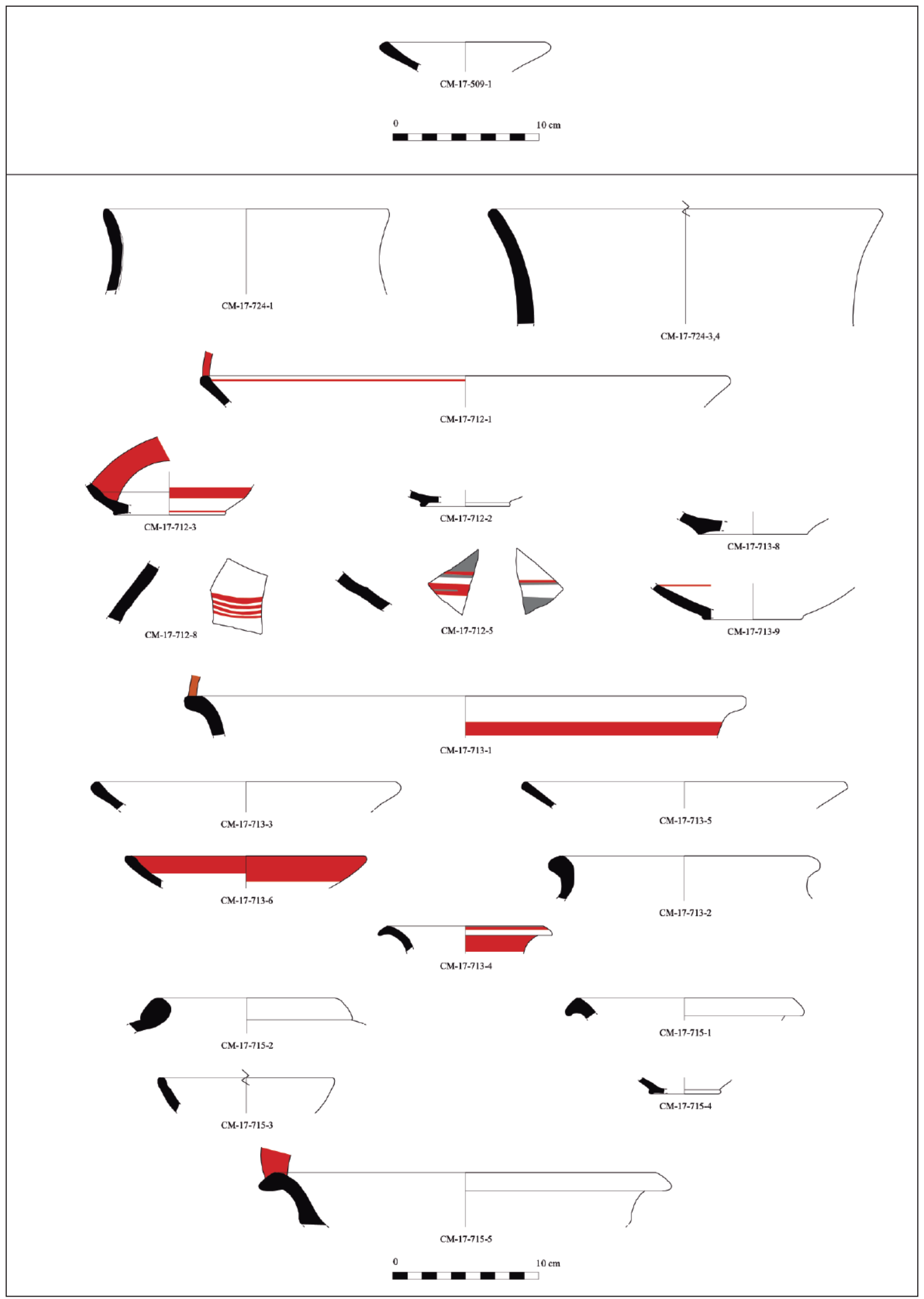

Figura 13: Materiales procedentes de las secuencias obtenidas en los sectores 5 y 7 . 


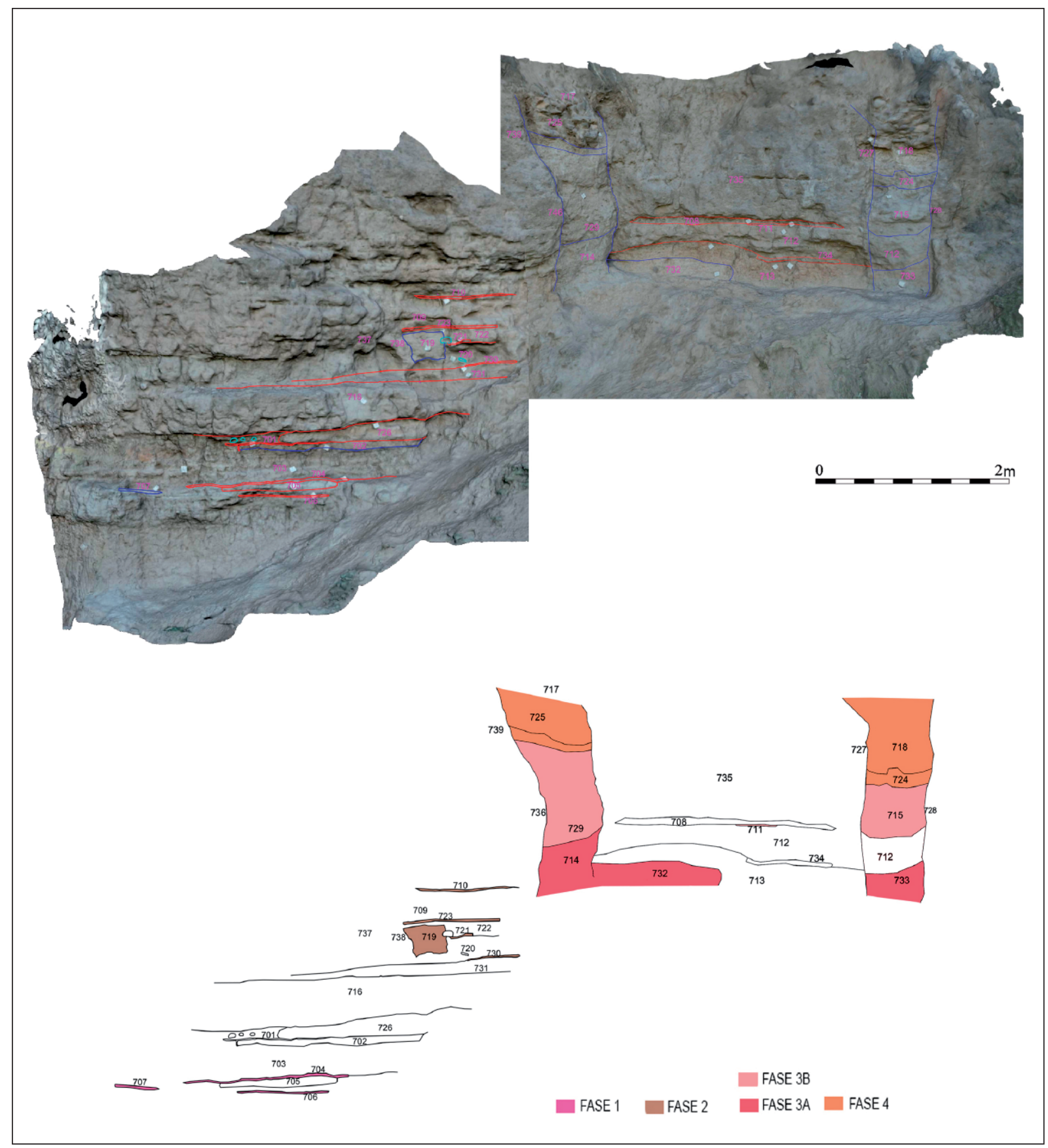

Figura 14. Ortofotografía y dibujo interpretativo del perfil obtenido en el sector 7.

con sus correspondientes niveles de anulación, que podrían responder en algunos casos a espacios abiertos o zonas de circulación. Debido a ello, y al carácter fragmentario de algunas unidades, resulta difícil realizar una lectura continua de la secuencia y establecer las relaciones entre las diferentes fases ocupacionales.
La parte inferior de la estratigrafía está definida por un potente nivel muy heterogéneo de tierra arcillosa con carbones, nódulos de cal y algunos restos cerámicos que arranca prácticamente de la base del cerro, oculto por 1,50 $\mathrm{m}$ de talud aproximadamente (UE724). De él proceden varios fragmentos de cerámica 
modelados a mano correspondientes a recipientes de almacenamiento, dos de ellos clasificables como vasos "à chardón" (fig. 13).

Este relleno sirve de base al primer nivel de ocupación (Fase 1), inaugurando una serie de superficies de uso o tránsito que se extiende entre la cota 13,20 y la cota 13,80 m s.n.m. Arranca con un nivel de ceniza de 1 a $2 \mathrm{~cm}$ de espesor y una longitud de $98 \mathrm{~cm}$ (UE-706), cubierto a su vez por un depósito de unos 5-10 cm de potencia compuesto por arcillas y cal (UE-705). Sobre él se sitúa un nuevo nivel de ceniza del mismo grosor (UE-704), aunque un poco más extenso (2,60 m documentados), y una superficie de arcilla roja y cal de 3 $\mathrm{cm}$ de espesor, que solo ha podido registrarse parcialmente en su extremo O (UE-707). De nuevo un relleno arcilloso compacto, en este caso con una superficie más regular y un espesor de unos $40 \mathrm{~cm}$, viene a anular a la ocupación anterior (UE-703). De él proceden varios fragmentos atípicos de cerámica común pintada, así como un fragmento de cerámica a mano con tratamiento superficial espatulado. Sobre este depósito se construye una plataforma de ladrillos de adobe de 10 $\mathrm{cm}$ de grosor y $2 \mathrm{~m}$ de longitud (UE-702) relacionada probablemente con la preparación de alimentos o el trabajo artesanal, ya que está cubierta en su totalidad por una capa homogénea de ceniza de 1,2 cm de espesor, que acaba rebasando los bordes de la misma para depositarse a sus pies (UE-701). La amortización de esta fase se realiza mediante dos potentes vertidos de arcilla y restos de adobe que pudieron servir para anular las estructuras precedentes y asentar el siguiente nivel de ocupación (UUEE-726 y 716). De hecho, estos depósitos presentan una cota análoga a los que separan las fases 1 y 2 de la secuencia obtenida en el sector 1 (entre 13,80 y 14,47 m s.n.m.) y podrían relacionarse también con la reforma general que se observa en el sector 5 .

A partir de aquí encontramos una sucesión de niveles de relleno y uso asociados a la Fase $2(14,47-$ 15,38 m s.n.m.). Comienza con un último depósito de nivelación de arcilla, carbones y cal (UE-731), de 15 cm de espesor máximo, donde pudieron documentarse dos paredes de ánforas de producción local/regional indeterminadas y varios fragmentos atípicos de cerámica común a torno. Sobre este se dispone un nivel de uso de $2 \mathrm{~cm}$ de grosor y más de $2 \mathrm{~m}$ de longitud (UE-730), amortizado por un nuevo paquete de arcilla y restos cerámicos de 20-30 $\mathrm{cm}$ de potencia (UE-720). La única estructura clara se desarrolla a continuación. Consiste en un muro de adobe o más probablemente tapial que se asienta en la UE-720 mediante una pequeña fosa de cimentación de unos $15 \mathrm{~cm}$ de profundidad (UE-738).
El muro UE-719 conserva $32 \mathrm{~cm}$ de altura, una anchura de $44 \mathrm{~cm}$ y parece estar asociado a un nivel de uso que se adosa a la cara oriental (UE-721). Se trata en realidad de una capa de ceniza muy localizada que se sitúa sobre el relleno UE-720, extendiéndose levemente hacia el E. Al otro lado del muro este nivel de uso es imperceptible, aunque sí se aprecia un cambio en la composición de los sedimentos a esa misma cota, marcando el siguiente nivel de amortización (UE-722/737) que encontramos a ambos lados del muro UE-719. Sobre este vertido se asienta otro nivel de ceniza de similares características que el anterior (UE-723), aunque mucho más limitado en el espacio, pudiendo tratarse de una fogata o un hogar. Una vez más, un potente relleno compuesto por restos de adobe, arcilla compactada y algunos fragmentos muy rodados de cerámica (ánforas y cerámica común) anula esta actividad (UE709). La horizontalidad de su superficie facilita la instalación de un nuevo nivel de uso (UE-710), en este caso más extenso, con 2-3 cm de grosor y una longitud que supera el metro. Podría estar asociado al muro UE-714 de la Fase 3, aunque la atonía de los depósitos y la dificultad para trabajar a esta cota limitaron la lectura de la secuencia.

Ello obligó a trasladar el área de intervención hacia el E, donde era posible registrar los niveles más altos de los perfiles. Aquí se pudieron identificar hasta 3 episodios constructivos, el primero de los cuales (Fase 3A: 15,38 m s.n.m.) estaría formado por dos muros de adobe o tapial, uno al E (UE-714) y otro al O (UE-733). Ambos tienen una anchura de unos $75 \mathrm{~cm}$ y están construidos con arcilla gris muy compactada, aunque solo se ha podido documentar su extremo superior, ya que la mayor parte de la estructura se encuentra bajo el talud que cubre esta parte del perfil. Al primero parece adosársele un muro o banco del mismo material (UE-732), del que se ha documentado una altura de $30 \mathrm{~cm}$ y una longitud de 1,56 m. Esta estructura se encuentra amortizada por un relleno de restos de adobe y cal procedente probablemente del desmantelamiento de sus propios alzados (UE-713). Este depósito ofreció un repertorio cerámico abundante, destacando las ánforas de producción local/ regional y la cerámica común a torno, representada por cuencos, lebrillos y vasos de distintos formatos, la mayoría decorados con las características bandas y líneas color rojizo. A ellos se suman el borde de un recipiente de cocina y algunos restos residuales de cerámica modelada a mano de cocina y almacenamiento (fig. 13). La UE-713 está cubierta, a su vez, por un segundo relleno de matriz arcillosa (UE-712) que sirve de base para el nivel de uso de la siguiente estructura. Aquí se registró 
de nuevo una amplia nómina de restos cerámicos, principalmente anfóricos (hasta 11 individuos diferentes si tenemos en cuenta las paredes identificadas), seguidos por las producciones comunes a torno, especialmente los cuencos y los vasos globulares, algunos de cronología avanzada dentro del Hierro II (fig. 13). Entre ambos rellenos se identificó, además, una superficie rojiza más endurecida de 4 a $6 \mathrm{~cm}$ de grosor y poco más de $1 \mathrm{~m}$ de longitud (UE-734), que pudo ser resultado de un uso puntual (¿hoguera?) o una alteración superficial del estrato subyacente. El segundo episodio (Fase 3B: 15,9016,30 m s.n.m.) lo conforman de nuevo dos muros de tapial (UUEE-715 y 729) que se asientan directamente sobre los anteriores mediante zanjas de cimentación (UUEE-728 y 736). Ambos presentan la misma anchura (75-80 $\mathrm{cm}$ aproximadamente) y un alzado variable, oscilando entre los $65 \mathrm{~cm}$ del muro E (UE-715) y los $100 \mathrm{~cm}$ del muro O (UE-729). Su orientación es respectivamente $\mathrm{NE}$ y N-NO, lo que invita a pensar que pudieron encontrarse formando una esquina varios metros hacia el S, en la parte hoy desaparecida. En el espacio entre los dos muros (que alcanza en el perfil los 3,20 m) se documentó una capa de ceniza de 2,5 cm de espesor que podemos interpretar como el nivel de uso de la estancia (UE-711). Sobre ella se registraron algunos restos cerámicos, en especial un borde de ánfora Pellicer D al que podemos atribuir cronología del s. III a.C. (Ferrer y García 2008: 211-212) y que se mantuvo en el perfil. Aparte de estos, los únicos materiales recuperados de esta fase proceden de la base del muro UE-715, donde se extrajo otro borde de ánfora de producción local, en este caso una variante evolucionada del tipo Pellicer $\mathrm{B} / \mathrm{C}$, y varios fragmentos de cerámica común: bordes y paredes de cuencos, lebrillos y vasos de almacenamiento, algunos con decoración pintada, además de restos residuales de recipientes a mano de gran formato (fig. 13). Esta estructura fue amortizada por una serie de depósitos de arcilla poco compacta y cantos (UUEE-708 y 735) que terminan colmatando el espacio entre los dos muros hasta alcanzar su cresta.

De la última fase constructiva, la Fase 4 (16,40 m s.n.m.), solo han podido documentarse dos muros de similar anchura y orientación (UUEE-718 y 717) realizados en mampostería. Se trata en realidad de cimientos/ zócalos de entre 60 y $80 \mathrm{~cm}$ de alzado insertos parcialmente en los niveles de amortización previos a través de zanjas de cimentación (UUEE-727 y 739). Están construidos con bloques irregulares de piedra caliza de mediano tamaño (en torno a $15 \times 20 \mathrm{~cm}$ ), toscamente careados al exterior, formando dos hiladas rellenas al interior con ripio, cantos de río y barro, sobre los que se situaría un alzado de adobe o tapial. Lamentablemente, la altura del perfil en este punto ha impedido intervenir en condiciones de seguridad en la parte superior de los muros, así como en los depósitos que se disponen entre ellos, por lo que no se han podido identificar los niveles de uso asociados. Estos parecen ser, no obstante, contemporáneos a las estructuras de similares características documentadas en los sectores anteriores y correspondientes a las últimas fases de ocupación del yacimiento.

No resulta fácil, dada la escasez de elementos constructivos, otorgar una cronología relativa a la secuencia obtenida en este sector. Parece evidente, por su posición y por los materiales registrados, compuestos en su totalidad por cerámicas a mano, que los depósitos más profundos corresponden a un momento pleno del Hierro I (s. VII a.C.), mientras que los niveles de ocupación que se superponen a ellos (Fase 1) podrían fecharse a lo largo del s. VI a.C. La Fase 2, separada de los niveles previos por potentes depósitos de amortización y preparación similares a los de los sectores 1 y 5 , pertenecería por tanto al s. V a.C. A partir de aquí observamos una laguna en la parte central de la secuencia que parece abarcar el final de este siglo y el inicio del siguiente. La Fase 3 supone tanto la amortización de las estructuras precedentes como una nueva construcción, cuya vida se extendería durante el s. IV a.C. La reforma de la Fase 3B se situaría con mayor precisión entre fines del s. IV e inicios del III a.C. En consecuencia, la estructura documentada en la Fase 4 debe corresponder a mediados del s. III a.C., coincidiendo con el proceso de petrificación de la arquitectura en tierra que afecta por igual en esta cota a los distintos sectores del yacimiento.

\section{SÍNTESIS DE LAS FASES DE OCUPACIÓN}

Hemos tratado de establecer una correspondencia entre los distintos niveles y fases de ocupación identificados en estos sectores del yacimiento y los registrados por las excavaciones realizadas en los años setenta (fig. 15). En el caso de la elevación oriental, hemos referenciado los perfiles resultantes del corte F de 1974 y V-20 de 1976, una vez escalados, situándolos a cota con la superficie actual del cerro con el fin de compararlos con las secuencias obtenidas en la campaña de 2017. Para ello nos hemos apoyado en el nuevo levantamiento planimétrico, usando como base las curvas de nivel correspondientes a los bordes del tell que, grosso modo, se han mantenido estables desde el cierre 


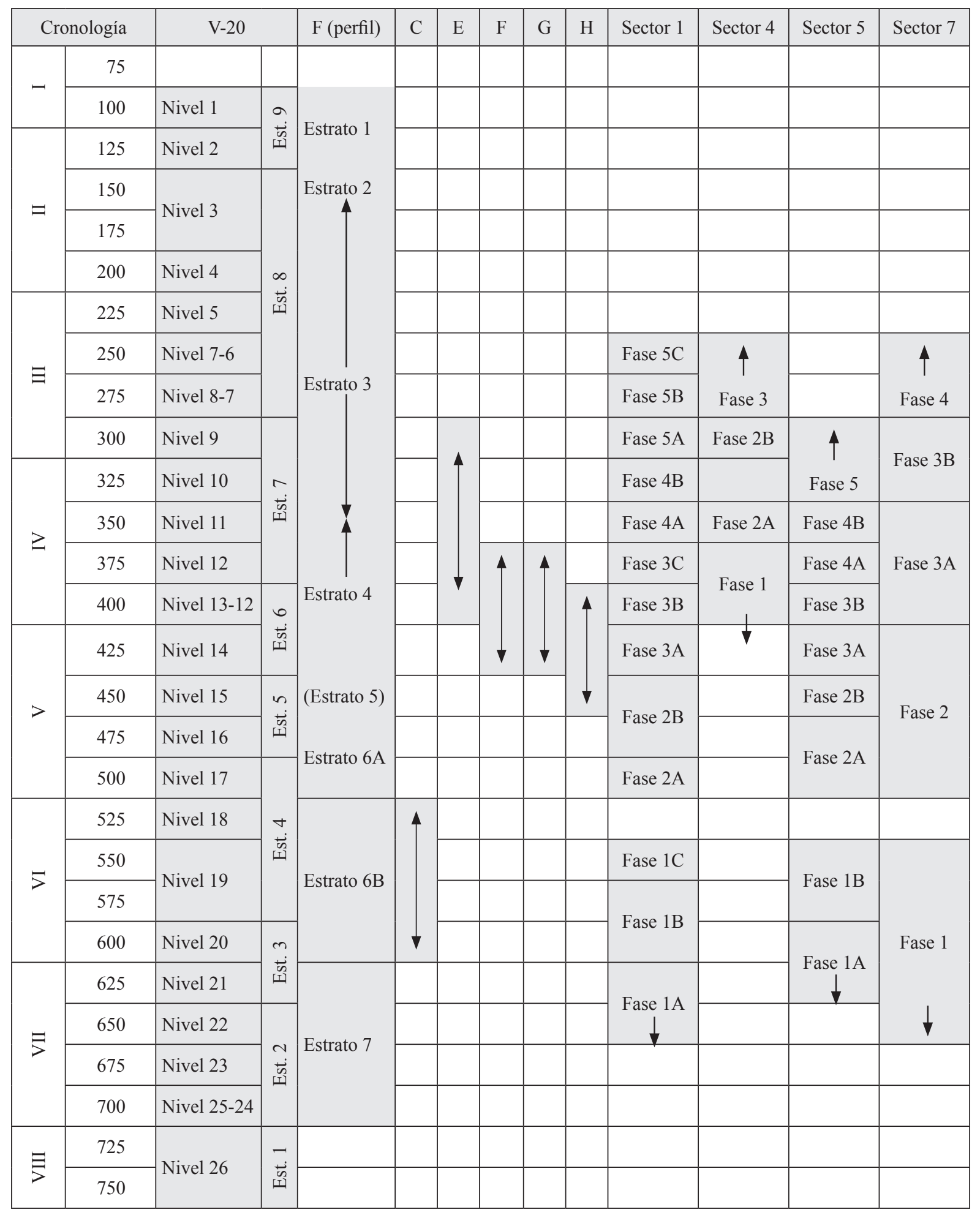

Figura 15. Propuesta de correspondencia estratigráfica y cronológica entre los niveles y fases de ocupación registrados en las excavaciones de 1974-1976 y en los perfiles intervenidos en 2017. En los cortes C, F, G y H de la elevación occidental no se describe más de una fase de ocupación. En los otros casos las flechas corresponden a fases cuyos límites inferiores o superiores no son nítidos, por lo que pueden tener su origen o prolongarse en niveles no registrados. 
de la cantera en torno a los 19 m s.n.m. La única excepción la constituye el sector 4 , cuyos estratos superiores han sido parcialmente destruidos por la acción de las máquinas. A ello hay que sumar, además, el cambio de cota que se produce en esta parte del cerro, descendiendo ligeramente hacia el norte en dirección al arroyo Almonázar, lo que explica que los niveles de ocupación documentados aparezcan sensiblemente más bajos, 1 $\mathrm{m}$ aprox. con respecto a los demás sectores estudiados (fig. 7). Por lo que respecta a la elevación occidental, la desaparición de buena parte de la secuencia arqueológica y la ausencia de referencias absolutas nos impide adaptar con fiabilidad las cotas recogidas en las planimetrías publicadas. Ni siquiera es posible situar las cuadrículas en la superficie del cerro, ya que los sectores excavados fueron posteriormente desmantelados y no han quedado huellas evidentes de las mismas en los perfiles (fig. 7). Aun así, la cronología ofrecida por los contextos exhumados, pertenecientes posiblemente al sector industrial del primitivo asentamiento, permite correlacionarlos con las fases registradas en la elevación oriental. Cabe advertir, no obstante, que no se ha llevado a cabo una revisión crítica de estas excavaciones antiguas, ya que excedería los límites y propósito de este trabajo, por lo que se acepta, con algunos matices que al cabo señalaremos, la datación y la interpretación ofrecida por sus excavadores.

Los niveles antrópicos más antiguos solo se han registrado, hasta el momento, en el corte V-20, donde se plantea como hipótesis la existencia en el nivel 26 (Estructura I) de una primera fase de ocupación compuesta por cabañas de planta oval y adobe fechada en la segunda mitad del s. VIII a.C. (Pellicer et al. 1983: 57). Lo mismo puede decirse de la siguiente fase, que abarca la mayor parte del s. VII a.C. (Estructura II). Aquí las evidencias se limitan a la presencia en el nivel 25 de cantos rodados de gran tamaño que podrían pertenecer a la base de un muro (fig. 6), así como otros cantos de menor tamaño interpretados por los excavadores como restos de un pavimento (Pellicer et al. 1983: 57). La ausencia de estructuras claras es extensiva al resto de las secuencias que han alcanzado estas cotas, como el Estrato VII del corte F (fig. 4) y los niveles de base del sector 7 (UE-724). Solo en el sector 1 se observaron unos restos de adobe que podrían pertenecer a un muro (UE-153) aunque, como se ha advertido, no llegó a excavarse por motivos de conservación.

A partir de este momento (último cuarto del s. VII a.C.) se inaugura una serie de episodios constructivos que se suceden a lo largo del último tramo del Hierro I, siendo especialmente elocuentes en la Fase 1 de los sectores 1 y 5 , mientras que en el sector 7 la ausencia de estructuras nos ha llevado a interpretar los niveles de uso documentados como un espacio abierto. A esta fase pertenecen también las construcciones registradas en los niveles 21-20 y 19 del corte V-20 (fig. 6), así como en el Estrato 6B del corte F (fig. 4). La primera, fechada en torno al 600 a.C. (Estructura III), está formada por un muro de ladrillos de adobe dispuestos en horizontal y vertical sobre una base de cantos de gran tamaño, con un ancho medio de $55 \mathrm{~cm}$ y una orientación aproximada N-S. La segunda, que mantiene prácticamente las mismas técnicas constructivas, medidas y orientación, parece corresponder a una refacción del anterior (Estructura IV), la cual pudo haber tenido lugar en la primera mitad del s. VI a.C. Ambos casos parecen estar asociados además a varios pavimentos de arcilla y cal o superficies de uso de tierra apisonada, como puede apreciarse en las secciones y fotografías publicadas (Pellicer et al. 1983: 57, fig. 13-15, lám. IV). Por lo que respecta al corte F, se identificó en el lado norte del perfil un muro de ladrillos de adobe de casi $1,10 \mathrm{~m}$ de altura, parcialmente amortizado por un nivel de derrumbe donde se aprecian ladrillos procedentes probablemente de su destrucción. Su excavador dató este estrato, a partir de los escasos materiales recogidos, en torno al s. VI a.C. (Martín de la Cruz 1976: 15, 25). Ello es coherente con los rasgos constructivos de la estructura y su cota (aproximadamente 13,4 m s.n.m. en su base), si la comparamos con el resto de las secuencias obtenidas en esta elevación. Es también en este momento cuando parece extenderse la ocupación hacia la parte oeste del cerro, más próxima al antiguo cauce del Guadalquivir, como se desprende de los depósitos excavados en el corte C, que se sitúan directamente sobre los niveles naturales de la terraza aluvial (Ruiz Mata y Vallejo 2002: 199). A falta de un estudio más profundo de este sector del yacimiento, podemos plantear a modo de hipótesis que el barrio industrial que se ha identificado en la elevación occidental tuviera su origen a finales del s. VII o inicios del VI a.C.

El final de este horizonte está asociado, como se ha venido advirtiendo más arriba, a una serie de depósitos de relleno, que acaban amortizando las construcciones del Hierro I, y unos potentes niveles de cimentación que las separan netamente de las estructuras que se suceden a lo largo de los siglos siguientes. Estos episodios, detectados en los sectores 1 y 7 prácticamente a la misma cota y con una diferencia de $40 \mathrm{~cm}$ con respecto al 5, se han interpretado como una interrupción temporal de la ocupación -al menos en esta zona-, que se extendería durante las últimas décadas del s. VI, y una 
posterior remodelación general del hábitat en los primeros compases del s. V a.C. La propia composición heterogénea de los depósitos, con algunas evidencias de actividades antrópicas puntuales (hogueras, vertidos de detritus), y la clara discontinuidad -tanto estratigráfica como arquitectónica- de las estructuras con respecto a las siguientes fases, nos llevan a pensar que estas quedaron abandonadas y a la vista antes de la instalación de los nuevos edificios. Es lo que se observa también en los niveles 18 y 17 del corte V-20 (fig. 6), aunque en este caso el reinicio de la actividad antrópica -cuyos niveles de uso pueden verse en el perfil- no está asociado a episodios constructivos, y en el Estrato 3A del corte F (fig. 4), que colmata definitivamente el muro identificado en el estrato anterior (Martín de la Cruz 1976: 15), si bien se ha puesto en duda que ello significara un hiato poblacional (Escacena 1993: 193).

El nuevo horizonte constructivo que se establece a inicios del s. V a.C. es muy evidente en la Fase 2 de los sectores 1,5 y 7 , sobre los que se desarrolla, como se ha visto, una secuencia de estructuras que se extiende de forma prácticamente ininterrumpida a lo largo del Hierro II. Esta fase tiene también su correspondencia en el corte V-20, quizá en un momento ligeramente posterior, en el segundo cuarto del s. V a.C. Esa es la fecha que sus excavadores asignan a los niveles 16 y 15 (Estructura V), donde se registró la cimentación de dos muros realizados con una base de piedras sin escuadrar y un segundo nivel de cantos rodados que se encuentran en ángulo recto (fig. 6). Mantienen una orientación casi cardinal, aunque aparecen desplazados $30 \mathrm{~cm}$ al E en relación con los muros de las Estructuras III y IV, por lo que incide en la discontinuidad que se observa entre finales del Hierro I y del Hierro II. En el interior de la estancia, adosado al muro E-O (el más ancho, con $70 \mathrm{~cm}$ ), se dispuso un hogar de piedras semicircular, mientras que el muro N-S presenta indicios de destrucción tanto al interior como al exterior de la vivienda que pudo haber tenido lugar a mediados de la misma centuria (Pellicer et al. 1983: 57-58, fig. 12). Es posible atribuir también a este momento el Estrato 5 del corte F, en el que se documenta un muro de adobes que «rompe, se apoya y superpone» parcialmente al muro del Estrato 6B (fig. 4), y cuyo límite superior está formado por un conglomerado de restos de adobe procedentes de la destrucción del muro, caídos probablemente en su nivel de habitación (Martín de la Cruz 1976: 15-16).

Parece que la estructura erigida en el corte V-20 fue reconstruida posteriormente en los niveles 14 y 13 (Estructura VI), en este caso con una simple base de cantos rodados y un alzado de adobe (fig. 6) fechados entre finales del s. V e inicios del IV a.C. (Pellicer et al. 1983: 58). Esta nueva construcción podría ser contemporánea a las estructuras de la Fase 3 en los sectores 1 y 5, al tránsito entre las Fases 2 y 3 en el sector 7, a los primeros niveles de la Fase 1 en el sector 4, así como al Estrato 4 del corte F (fig. 4). En este último se observa un potente relleno de 1,10 m de espesor que debió corresponder con un hiato en la ocupación este sector, que pudo prolongarse a lo largo de casi todo el s. IV a.C. a juzgar por el material extraído del perfil (Martín de la Cruz 1976: 19-20, 26-27, figs. 6-8). No obstante, la tónica general que se extrae de los distintos cortes es la de un hábitat extenso, denso y dinámico que abarca en este momento la totalidad del yacimiento, al menos en su parte conservada. Ello es extensivo a la elevación occidental, donde se documentó un conjunto de estructuras de producción pertenecientes a un posible barrio industrial vinculado al puerto fluvial (fig. 5). Las más antiguas (corte $\mathrm{H}$ ) se dataron entre mediados del s. V y el primer cuarto del IV a.C. (Ruiz Mata y Córdoba 1999: 97), mientras que el resto (cortes F y G) parecen ser ligeramente posteriores, entre finales del s. V y un momento avanzado del IV a.C. (Fernández Gómez et al. 1979: 75). Lamentablemente, como se vio al inicio, los estratos superiores ya habían sido desmantelados a mediados de los años setenta, por lo que resulta imposible conocer la evolución de este sector productivo en los siglos posteriores. La única excepción parece ser la estancia excavada en el corte E, ubicado en el extremo suroriental de la elevación, cuyos rellenos ofrecieron un abundante repertorio material que puede fecharse a lo largo del s. IV e incluso inicios del III a.C. (Fernández Gómez et al. 1979: passim).

Este es el arco cronológico de la siguiente etapa, que comprende las Fases 3C, 4 y 5A del sector 1, las Fases 1 y 2 del sector 4, las Fases 4 y 5 del sector 5, y la Fase 3 del sector 7. En todos los casos las estructuras reflejan una clara continuidad con respecto a las fases precedentes, tanto por su posición estratigráfica, orientación, materiales y técnicas, como por los rasgos formales y funcionales de los espacios resultantes, reproduciendo la misma dinámica constructiva. En algunas ocasiones los muros se apoyan o adosan a los anteriores y los pavimentos se implantan directamente sobre los rellenos que amortizan las estancias previas, elevando la cota de uso casi $1 \mathrm{~m}$. Ello se aprecia también en el corte V-20, donde se instala una nueva estructura que abarca los niveles 12 al 9 (Estructura VII). Se trata de un muro de 65 $\mathrm{cm}$ de ancho y orientación N-S, construido con una cimentación de cantos rodados y alzado de adobe, perpendicular a una línea de cantos rodados en sentido E-O 
con el que parece formar también una esquina en ángulo recto, aunque desplazada unos $30 \mathrm{~cm}$ al sur con respecto a la anterior (Pellicer et al. 1983: 58, fig. 11). Estas estructuras se encuentran asociadas en su base a un pavimento de arcilla apisonada que se reconstruye sucesivamente en los niveles superiores, al menos hasta el 9 (fig. 6). En el corte F, por su parte, una bolsada de relleno, que rompe aparentemente los restos de una estructura de tapial, sirve de base a una nueva fase constructiva (Estrato 3 ) constituida por dos muros sucesivos (fig. 4). El primero es el típico paramento de ladrillos de adobe, similar a los documentados en los demás sectores, que presenta una altura conservada de $60 \mathrm{~cm}$. El segundo, en cambio, es un zócalo de piedras unidas entre sí con mortero de barro de unos $40 \mathrm{~cm}$ de altura, que rompe y se encaja en la anterior en su zona central superior (Martín de la Cruz 1976: 20-21).

Este último muro, perteneciente ya a una fase posterior, inaugura un nuevo horizonte constructivo que puede observarse en prácticamente todos los sectores de la elevación oriental. Se caracteriza por la introducción de potentes cimientos-zócalos de mampostería careada sobre los que se colocaría un alzado de adobe o tapial. La coetaneidad de este proceso de petrificación de la arquitectura doméstica en la primera mitad del s. III a.C. queda demostrada por las cotas de base de los muros de piedra documentados en los sectores 1 (Fase 5B y 5C), 4 (Fase 3), 5 (fuera del corte) y 7 (Fase 4), que se sitúa en torno a los 16 m s.n.m. a excepción del sector 4, que como se ha visto mantiene una altura absoluta ligeramente inferior. A ellos debemos sumar los registrados en corte V-20, que arrancan también a esta cota (fig. 6). Nos referimos a los cimientos de bloques sin escuadrar del nivel 8, que prosiguen en los niveles 7 y 6 (Estructura VIII) y estarían asociados a niveles de habitación de pequeños cantos rodados y tierra apisonada (Pellicer et al. 1983: 58, Lám. II,1). Muros de estas características son perceptibles, además, en otros sectores del cerro, generalmente anchos y potentes, continuando hasta los niveles superiores de la secuencia.

Las últimas fases de ocupación del oppidum protohistórico solo son reconocibles en el corte V-20 (fig. 6), ya que en el $\mathrm{F}$ únicamente se describió un posible nivel de habitación aislado en el extremo norte del Estrato II, restos de adobe, tapial y diversas bolsadas de material de relleno que se extienden hasta el nivel superficial (Estrato I) (Martín de la Cruz 1976: 21-22), mientras que la limpieza de perfiles llevada a cabo en 2017 no llegó en ningún caso a esa cota por motivos de seguridad. En el nivel 5 se localizó una nueva estructura, esta vez de cantos rodados, con alzado de adobes y un grosor de $58 \mathrm{~cm}$. Mantiene prácticamente la misma orientación que las anteriores, aunque ligeramente girada hacia el $\mathrm{N}$, lo que provoca un claro desplazamiento, sobre todo del muro orientado N-S. El interior de la habitación era de tierra rojiza con abundantes cenizas y en su límite $\mathrm{E}$ aparecieron dos recipientes de cocina intactos, situados en el interior de un hogar. Este hecho se interpretó como un abandono precipitado que sus excavadores situaron en el contexto de la II Guerra Púnica, a finales del s. III a.C., aunque a continuación señalaban la presencia de un nuevo pavimento de tierra apisonada en el nivel inmediatamente posterior, lo que estaría indicando la continuidad de la Estructura VIII hasta los inicios del s. II a.C. (Pellicer et al. 1983: 58, fig. 10, Lám. I,3). Un último nivel constructivo fue identificado en el nivel 2 (Estructura IX). Consistía en un muro de mampuestos y cantos rodados muy destruido, atravesando el ángulo $\mathrm{N}$ del corte en sentido E-O y asociado a restos de un encachado de grava, que podría fecharse ya en la segunda mitad del s. II a.C. (Pellicer et al. 1983: 58, fig. 10, Lám. I,2). Por último, el nivel 1, muy removido por las labores agrícolas, cerraría la secuencia con unos materiales que permiten situar el final del hábitat en torno al cambio de siglo (Pellicer et al. 1983: 55).

\section{NUEVOS APUNTES SOBRE LAS TÉCNICAS CONSTRUCTIVAS}

Una de las principales aportaciones de la intervención realizada en 2017 ha sido la posibilidad de profundizar sobre las técnicas constructivas empleadas en el yacimiento y su evolución a lo largo de la Edad del Hierro.

Desde el punto de vista arquitectónico nos encontramos ante estructuras de planta rectangular y tamaño medio, entre $2 \mathrm{~m}$ las más pequeñas y 3,5 $\mathrm{m}$ las de mayores dimensiones (cf. Díes Cusí 2001: 92). Aunque en los perfiles es difícil determinar si se trata del ancho o la longitud de la habitación, en ambos casos sugieren espacios amplios, presumiblemente de un solo piso. Los muros siguen una orientación predominante N-S/E-O, ligeramente desviada hacia el N-NE en casi todas las fases definidas, si bien tampoco son infrecuentes otras orientaciones, especialmente la SO-NE, que encontramos en las estructuras más recientes, coincidiendo con la aparición de los zócalos pétreos. Parece tratarse en su mayoría de estructuras domésticas, o bien de espacios asociados a las mismas, a juzgar por su forma y tamaño, acabados e instalaciones, así como por los materiales registrados en sus niveles de construcción y amortización, generalmente cerámicas comunes y ánforas. 
Los muros están realizados con ladrillos de adobe y, en ocasiones, con tapial. Pueden construirse sobre los depósitos de nivelación previos o encajarse en ellos mediante una pequeña zanja de cimentación, cuando no se asientan directamente sobre los restos de las estructuras anteriores para ganar mayor estabilidad. A veces suelen llevar una cama de cantos rodados, de una o dos hiladas, que además de aportar solidez pudo servir como elemento de aislamiento y drenaje de la humedad (fig. 16, B), pero también son frecuentes los muros construidos completamente en tierra desde su propia base (fig. 16, A). Solo en las últimas fases de ocupación (s. III a.C.) se generaliza, como hemos visto, el zócalo de mampuestos careados, relleno con ripio y tierra (fig. 16, C). Resulta muy llamativa la tardía incorporación de esta solución constructiva, muy común en el ámbito fenicio-púnico (Prados 2003: 159-160), que encontramos en el sur de la península ibérica desde los inicios de la colonización fenicia (ibd: 47-48, Díes Cusí 2001: 81) y que es habitual en otros yacimientos turdetanos, como Niebla, Tejada la Vieja o Carmona (Serrano 2015: 327-328). Ello podría deberse, probablemente, a la escasez de piedra en la vega del Guadalquivir frente a la abundancia de cantos de río, que habrían perpetuado el uso de ese tipo de cimentaciones sencillas hasta finales de la Edad del Hierro, conformando un rasgo característico de la tradición constructiva de las poblaciones ribereñas, como puede observarse también en Sevilla (García y González 2007) o Alcalá del Río (Ferrer y García 2007).

Los muros de adobe están construidos, por lo general, con ladrillos rectangulares de entre $40-50 \mathrm{~cm}$ de largo por 25-30 de ancho y $10 \mathrm{~cm}$ de grosor, o bien con ladrillos cuadrangulares de unos $35 \mathrm{~cm}$ de lado, aunque se aprecia una relativa variabilidad entre unas fases y otras (cf. Pellicer et al. 1983: 57-58). Suelen estar realizados con arcilla rojiza o marrón, y unidos con una argamasa de barro fino más claro que deja unas llagas de 1-2 cm, por lo que resulta fácil diferenciarlos de los depósitos de amortización y nivelación, en los que se utiliza mayoritariamente arcilla grisácea. A veces están recubiertos de un enlucido de cal que puede alcanzar con el tiempo un espesor considerable. Se usa indistintamente el aparejo a soga, a tizón, y muy raramente a soga y tizón, pudiendo responder a la propia entidad o función del paramento (muro de cierre, tabique de compartimentación, etc.). Solo en una ocasión, en los niveles 21-19 del corte V-20, se ha registrado un aparejo singular, formado por una hilada de ladrillos en horizontal y otra en vertical junto a los anteriores, «como refuerzo del muro» (Pellicer et al. 1983: 57, fig. 13-14), pero ignoramos si se trata de un hecho aislado o una solución común, al menos en las fases constructivas más antiguas. Por lo que respecta a sus medidas, los ejemplos conservados van desde los 45 hasta los $70 \mathrm{~cm}$ de ancho, dependiendo de la función desempeñada (muros maestros o tabiques), siendo la medida más frecuente entre 50 y 60 , salvo los zócalos pétreos más tardíos, que oscilan ya entre 60 y $80 \mathrm{~cm}$ de ancho, en la línea de otros yacimientos protohistóricos de la región (Díes Cusí 2001: 81, Serrano 2015: 337-338). Metrológicamente, estas estructuras se mantienen dentro de los estándares introducidos por los fenicios en la península ibérica a inicios de la Edad del Hierro, tanto en sus asentamientos costeros como en las comunidades establecidas en el interior (Belén et al. 1993: 223-226, cf. Díes Cusí 2001: passim), correspondiendo a las distintas unidades de codo $(50-55 \mathrm{~cm})$ que se mantuvieron posteriormente en la arquitectura púnica (Prados 2003: 196, Barresi 2007: 2021) y que se adoptarán también en la ibérica (Prados 2007: 31) y en la turdetana (Serrano 2015: 375-376).

Las estancias documentadas suelen estar pavimentadas con lechadas alternas de arcilla y cal (fig. 16, D). Esta técnica la encontramos desde los niveles más antiguos (s. VI a.C.) hasta los más recientes, conviviendo con la introducción de los zócalos de piedra. Se trata de una forma de pavimentar bien conocida y atestiguada en los yacimientos protohistóricos del sur de la península ibérica (Díes Cusí 2001) y el Mediterráneo (Braemer 1982). Lo que singulariza a los suelos de Cerro Macareno es su potencia, alcanzando en ocasiones los $10 \mathrm{~cm}$ de espesor. Ello revela la larga vida de estas estructuras, que fueron reparadas periódicamente con las mismas técnicas, conservando probablemente también la misma función. No obstante, lo normal es que su grosor oscile entre 2 y $5 \mathrm{~cm}$, manteniendo generalmente su superficie limpia de residuos, lo que indica que su anulación no se debió a un abandono sino a una amortización intencionada para reparar o reconstruir la estructura. Volveremos sobre este tema más adelante. Un detalle interesante es la forma en la que los pavimentos se adosan a los muros (fig. 16, E). Suelen tener un acabado en media caña, a modo de rodapié, que se eleva sobre su superficie adosándose al enlucido del muro y garantizando así el aislamiento de la estancia. En ocasiones, utilizan para ello cantos rodados que se colocan entre el muro y el nivel sobre el que se asienta el pavimento, ayudando de este modo a generar la curvatura. Esta solución constructiva -con o sin cantos rodadosse utiliza tanto en el contacto entre los pavimentos y los muros, como en su relación con otras instalaciones domésticas como bancos o poyos, y es habitual en los niveles medios y superiores de la estratigrafía (desde la 


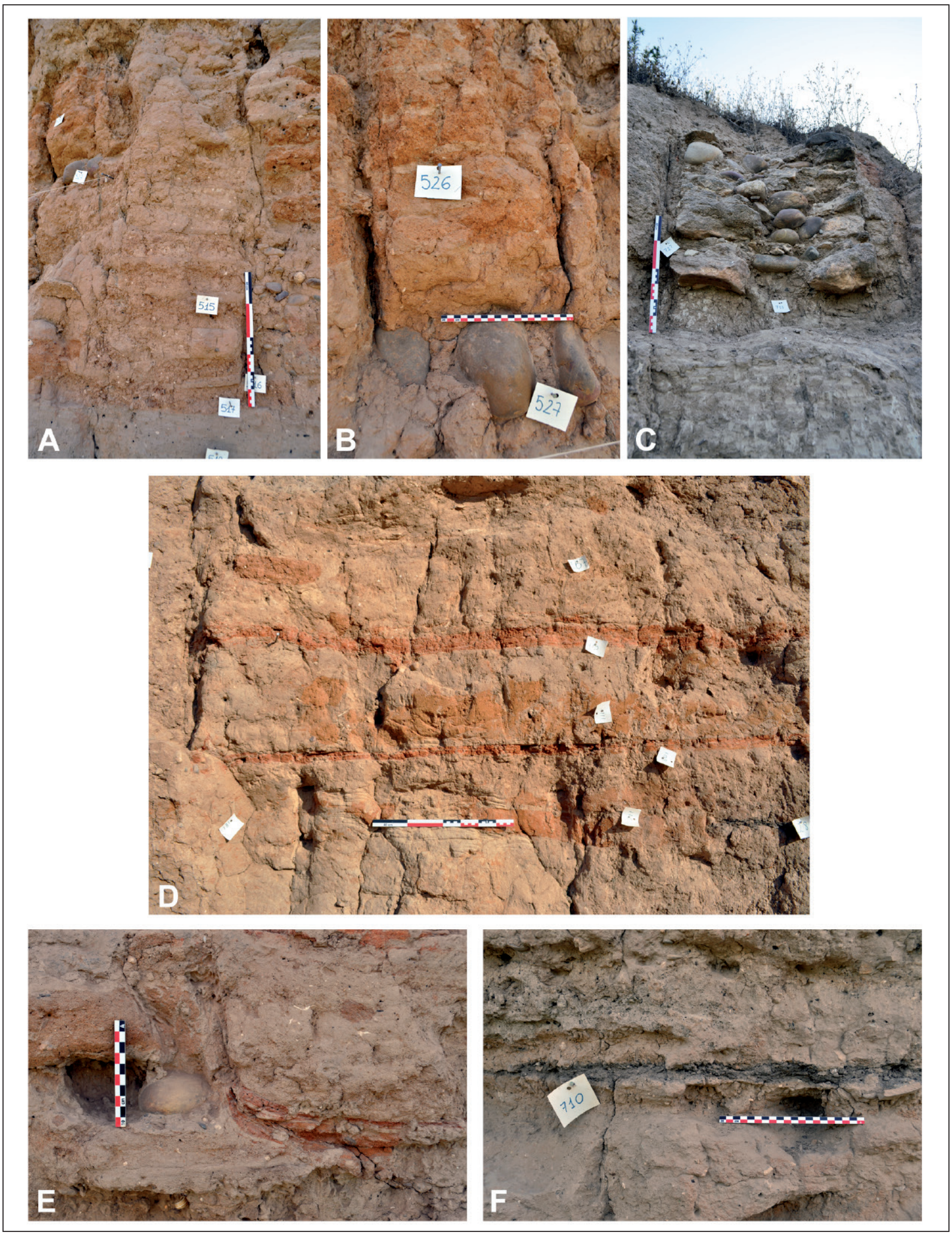

Figura 16. Imágenes de las soluciones constructivas de muros, pavimentos y niveles de relleno más frecuentes empleadas en el yacimiento durante el Hierro II.

ISSN: $1133-4525$ ISSN-e: $2255-3924$ 
Fase 2 de los sectores 1, 5 y 7), por lo que podemos deducir que constituye un rasgo característico de la arquitectura de Cerro Macareno, al menos desde mediados del I milenio a.C.

También se documentan otros tipos de niveles de uso, generalmente superficies no pavimentadas endurecidas por su uso o por la acción del fuego, en ocasiones cubiertas por tierra suelta, ceniza y detritus, o bien depósitos de ceniza relacionados con hogares (fig. 16, F). En el primer caso resulta difícil determinar si se trata de espacios abiertos o cerrados, o incluso de niveles de circulación exterior (calles, explanadas) salvo que estén relacionados claramente con elementos constructivos. Lo mismo se puede decir de los depósitos de grava y encachados, que pudieron corresponder tanto a rellenos de compactación como a espacios de tránsito, dada la extensión y horizontalidad que suelen presentar. Tanto en unos como en otros aparecen instalaciones de distinto tipo: bancos, poyos, hogares, o incluso plataformas de adobe, como la documentada en el sector 7. Los primeros pueden tener pavimentos adosados o estar revestidos de capas de arcilla y cal, mientras que los hogares y plataformas están asociados a restos de carbón, ceniza y basura derivados de su uso.

Como se ha visto, salvo cuando se produce un abandono más o menos dilatado en el tiempo, en cuyo caso las estructuras están sepultadas por depósitos irregulares de tierra y residuos domésticos, el ciclo vital de las construcciones turdetanas (las fases más antiguas no han sido completamente documentadas y presentan además una peor conservación) parece seguir siempre el mismo patrón (fig. 16, D). Durante el uso del edificio, este se mantiene y repara periódicamente mediante el enlucido de las paredes y el enlechado del suelo, o incluso se refuerza para garantizar su estabilidad cuando uno de los muros anuncia ruina, construyendo un nuevo paramento directamente sobre el propio piso. Eventualmente se disponen también elementos como hogares, bancos o poyos, que obligan a recrecer el pavimento o a revocar su contacto con estas instalaciones. Sin embargo, cuando el edificio está totalmente obsoleto se procede a destruirlo para construir otro justo encima, aprovechando la base de sus muros como cimentación de los nuevos. Las estructuras suelen desmocharse hasta una altura comprendida entre los 30 y los $70 \mathrm{~cm}$, vertiendo los escombros dentro de la habitación, sobre un pavimento limpio casi siempre de enseres o restos de basura. Sobre este depósito, que presenta una superficie irregular, generalmente inclinada desde la base de los muros hacia el centro de la habitación, se dispone un segundo nivel de arcilla compacta color grisáceo que sirve de nivelación para la siguiente fase constructiva. Será sobre su superficie donde se construya el nuevo pavimento, con o sin ayuda de un preparado de regularización realizado también en arcilla. Estos depósitos ofrecen a menudo cerámicas, restos faunísticos, carbón, etc. procedentes de los aportes de tierra utilizados en los rellenos, o que han sido vertidos como basura en los mismos, si bien su cantidad varía mucho entre unos sectores y otros o incluso entre unas fases constructivas y otras.

Con todo, a pesar de la abundante presencia de material residual en estos niveles secundarios y la aparición de restos in situ sobre algunos pavimentos, hogares o instalaciones, los contextos exhumados -compuestos principalmente por cerámicas comunes de cocina y mesa, ánforas y, en menor medida, vajilla fina importada- se muestran insuficientes a día de hoy para determinar la función exacta de estas estructuras, más allá de la doméstica. Resulta imprescindible, por tanto, la realización de nuevas intervenciones en los sectores conservados que saquen a la luz contextos amplios de las principales fases de ocupación de Cerro Macareno, o al menos de las más representativas de las etapas de transición, con objeto de estudiar en extensión sus rasgos arquitectónicos, constructivos y urbanísticos, así como las actividades desarrolladas por sus habitantes.

\section{CONCLUSIONES}

Con todo, el estudio de diagnóstico llevado a cabo recientemente ha permitido confirmar gran parte de las propuestas realizadas por sus primeros excavadores a mediados de los años setenta y avanzar en algunas de ellas, aportando un gran caudal de información sobre la extensión del yacimiento, su potencia estratigráfica, las fases de ocupación presentes, la organización espacial del hábitat y su evolución, sus rasgos arquitectónicos y constructivos, así como sobre la entidad y estado de conservación de los restos subyacentes.

Para empezar, se ha podido calcular la extensión actual de los restos conservados en las dos elevaciones, que suman poco más de $20000 \mathrm{~m}^{2}$, incluyendo los taludes, con respecto al tamaño original del cerro, que alcanzaba los $90000 \mathrm{~m}^{2}$. Ello supone una destrucción de más de tres cuartas partes de su superficie, o lo que es lo mismo, ha llegado hasta nosotros poco más del $20 \%$ del yacimiento para su investigación. En cuanto a su potencia estratigráfica, la elevación oriental mantiene aún su cota primitiva (19-18 m s.n.m.), lo que da lugar a perfiles profundos, de más de $7 \mathrm{~m}$ desde su base $(11 \mathrm{~m}$ s.n.m.) en la mayor parte de su perímetro, a excepción 
del $\mathrm{N}$, donde apenas supera los $5 \mathrm{~m}$. En cambio, la elevación occidental, que ya había perdido los niveles superiores de su estratigrafía, presenta perfiles más alterados, con una potencia de entre 4 y $5 \mathrm{~m}$ desde la base de la terraza (12,5 m s.n.m.) en la parte más alta (17 m s.n.m.), descendiendo hasta los $3 \mathrm{~m}$ en la cara $\mathrm{N}$ (14 m s.n.m.).

Asimismo, se ha confirmado la secuencia de ocupación establecida por las primeras intervenciones, aunque con algunos matices. A juzgar tanto por los materiales recogidos en superficie como, sobre todo, por el estudio comparado de las estratigrafías obtenidas en la elevación oriental, todo apunta a que el hábitat debió iniciarse en un momento indeterminado del s. VIII para terminar a finales del II a.C., mientras que, en la elevación occidental, ni la potencia de los depósitos conservados ni los materiales asociados permiten pensar en niveles anteriores al VI a.C. No obstante, sí se constatan evidencias de ocupaciones posteriores, aunque de poca entidad, que podrían haberse situado sobre el cerro, en sus laderas o en sus alrededores, en los sectores ya desaparecidos, aunque también es probable que una parte de los restos de época romana y medieval documentados llegaran desplazados por movimientos de tierra relacionados con la explotación de la cantera.

Por otro lado, se mantiene la distribución de las áreas funcionales propuesta en los años setenta, ya que el hábitat parece concentrarse principalmente en la elevación oriental, mientras que las estructuras de carácter industrial se disponen en la elevación occidental, más próxima al antiguo cauce del Guadalquivir, que se transforma a mediados del I milenio a.C. en un auténtico barrio industrial. En este sentido, a pesar de la tendencia horizontal que se aprecia en la mayor parte de los perfiles, las cotas absolutas obtenidas en los distintos sectores estudiados permiten adivinar los pequeños cambios topográficos que debieron existir durante su fase de actividad, y que habrían condicionado su desarrollo espacial, como el leve escalón que se observa en el extremo $\mathrm{N}$ de la elevación oriental, o el aumento de cota de la base del cerro en la elevación occidental, que pudo contribuir también a la separación física de las actividades artesanales con respecto al hábitat.

Las estratigrafías obtenidas en la elevación oriental demuestran también que la función de hábitat se extendió de forma prácticamente ininterrumpida a lo largo de todo el periodo de ocupación del yacimiento. Se advierte además una gran coherencia entre estas y las antiguas secuencias publicadas, especialmente el corte $\mathrm{V}-20$, cuyas fases coinciden grosso modo con las registradas en los perfiles estudiados en 2017. Aun así, se ha podido identificar una remodelación extensa en tres de los cuatro sectores intervenidos que parece suceder a un abandono temporal del hábitat, probablemente a finales del Hierro I. Está constituida por rellenos potentes y heterogéneos que amortizan las estructuras anteriores, por lo general muros de adobe muy precariamente conservados, en algunos casos sellados por niveles de uso puntuales, como hogueras o depósitos de ceniza. Sobre ellos se disponen -en ocasiones encajados por medio de zanjas- rellenos masivos de arcilla gris muy compactada destinados a nivelar el terreno y cimentar la siguiente fase constructiva. Esta inaugura en realidad una secuencia de estructuras, reparaciones, amortizaciones y reconstrucciones que se suceden en el tiempo sin aparente solución de continuidad hasta el final de la vida del antiguo oppidum. El mantenimiento de las mismas tipologías arquitectónicas, materiales, técnicas, medidas, orientaciones y funciones da fe no solo de la estabilidad del hábitat, sino también de la persistencia de las mismas tradiciones y formas de vida.

En este sentido, cabe destacar la continuidad de las formas constructivas a lo largo de las distintas fases identificadas y su enorme personalidad, que es extensiva al resto de los grandes establecimientos portuarios del Guadalquivir, como Ilipa (Alcalá del Río), Italica (Santiponce), Spal (Sevilla) o Caura (Coria del Río). Se aprecia obviamente una gran sintonía con la tradición arquitectónica fenicio-púnica, que se refleja no solo en la tipología edilicia y las técnicas constructivas, sino también en perduración de los patrones metrológicos de origen oriental, ya sea en las proporciones generales de los espacios como, sobre todo, en la modulación de las estructuras. No obstante, se desarrollan por otro lado soluciones particulares que solo pueden entenderse en clave local. Estas son el resultado de una larga evolución en la que los modelos orientales se van adaptando a las condiciones ecológicas del entorno y a las coyunturas económicas, sociales y culturales de sus pobladores.

Finalmente, cuarenta años después de las últimas excavaciones, hemos podido valorar el potencial científico y patrimonial que aún alberga Cerro Macareno. La profundidad y extensión de los depósitos arqueológicos subsistentes, el estado de conservación de los niveles de ocupación, su continuidad cronológica y su coherencia en relación con la secuencia cultural del Bajo Guadalquivir protohistórico, aportando nuevos datos sobre los momentos poco conocidos, como el tránsito entre el Hierro I y el Hierro II o el inicio de la presencia romana, así como la excelente legibilidad de las estructuras los contextos asociados, suponen un estímulo para el estudio sistemático de este yacimiento y el desarrollo de las estrategias de conservación y puesta en valor 
adecuadas con el fin de avanzar en el conocimiento y la difusión de este periodo histórico en la región.

\section{Agradecimientos}

Este trabajo es fruto en gran medida de una estancia de movilidad de profesores e investigadores sénior en centros extranjeros (Programa "Salvador de Madariaga") realizada en el Istituto di Studi sul Mediterraneo Antico de Roma en el verano de 2018 (PRX18/00285). Agradecemos al responsable de la estancia en el centro de destino, el Dr. Massimo Botto, su generosa acogida y el estímulo para llevar a término esta síntesis. Se enmarca en los proyectos de investigación "Tarteso Olvidado (en los Museos)" (PGC2018-097131-B-I00) y “La Construcción en el Valle del Guadalquivir en Época Romana. Tradición e Innovación en las Soluciones Arquitectónicas y los Procesos Tecnológicos, Económicos y Productivos" (HAR2015-64392-C4-4-P). Por su parte, las labores de campo fueron financiadas por el Departamento de Prehistoria y Arqueología de la Universidad de Sevilla y el Área de Cultura del Ayuntamiento de La Rinconada, a cuyos responsables agradecemos su inestimable apoyo. Asimismo, ha sido fundamental la ayuda prestada por los miembros del equipo de investigación del proyecto arqueológico, especialmente P. Albuquerque y L. Guillén Rodríguez, la colaboración de A. Mateos Orozco, N. Conejero Redondo e I. Romero Mata en el registro y documentación gráfica, y de J. García Cerezo, encargado de la realización de los levantamientos topográficos. Agradecemos a los profesores O. Rodríguez Gutiérrez y A.M. Sáez Romero, de la Universidad de Sevilla, sus sugerencias sobre distintos aspectos del proyecto y al personal del Museo Arqueológico y Paleontológico de La Rinconada (M.I. Rodríguez Achútegui, J. Navarro Perza y M. Garrido Martín) su apoyo logístico. Por último, es preciso mencionar la ayuda de los alumnos del Grado de Arqueología, que realizaron sus prácticas en el marco del proyecto.

\section{BIBLIOGRAFÍA}

Amberger, G. (1985): "Tierknochenfunde vom Cerro Macareno/Sevilla". Studien über frühe Tierknochenfunde von der Iberischen Halbinsel 9: 76-105.

Barresi, P. (2007): Metrología púnica. Milano, Athenaion.

Belén, M.; Escacena, J.L.; Anglada, R.; Jiménez, A.; Pardo, Ma ${ }^{\mathrm{a}}$. y y
(1993): "Arquitectura de tradición fenicia en Carmona (Sevilla)". Spal 2: 219-242. <http://dx.doi. org/10.12795/spal.1993.i2.09>.

Braemer, F. (1982): L'Architecture domestique du Levant à l'Âge de Fer. Paris, Recherche sur les Civilisations.

Díes Cusí, E. (2001): "La influencia de la arquitectura fenicia en las arquitecturas indígenas de la Península Ibérica (s. VIII-VI)", en D. Ruiz Mata y S. Celestino Pérez (eds.), Arquitectura oriental y orientalizante en la Península Ibérica: 69-121. Madrid, CSIC.

Escacena Carrasco, J.L. (1983): "Problemas en torno a los orígenes del urbanismo a orillas del Guadalquivir". Gades 11: 39-83.

Escacena Carrasco, J.L. (1987): "El poblamiento ibérico en el Bajo Guadalquivir”, en A. Ruiz y M. Molinos (eds.), Actas de las Primeras Jornadas sobre Mundo Ibérico: 273-297. Jaén, Ayuntamiento de Jaén-Junta de Andalucía.

Escacena Carrasco, J.L. (1993): "De la muerte de Tartesos. Evidencias en el registro poblacional". Spal 2: 183-218. doi: <http://dx.doi.org/10.12795/ spal.1993.i2.08>.

Fernández-Chicarro y de Dios, C. (1974): “Adquisiciones del Museo Arqueológico de Sevilla”. Bellas Artes 33: 31-34.

Fernández Gómez, F.; Chasco Vila, R. y Oliva Alonso, D. (1979): "Excavaciones en 'El Cerro Macareno'. La Rinconada. Sevilla (Cortes E-F-G. Campaña 1974)". Noticiario Arqueológico Hispánico 7: 7-93.

Ferrer Albelda, E. (2017): "La colonización fenicia en la Tartéside: estrategias y fases", en S. Celestino y E. Rodríguez (eds.), Territorios comparados: los valles del Guadalquivir, el Guadiana y el Tajo en época tartésica: 11-46. Mérida, IAM-CSIC.

Ferrer Albelda, E. y García Fernández, F.J. (2007): "Primeros datos sobre la Ilipa turdetana”, en E. Ferrer, A. Fernández, J.L. Escacena y A. Rodríguez (eds.), I Congreso de Historia de Alcalá del Río: Ilipa Antiqua. De la Prehistoria a la Época Romana: 103130. Alcalá del Río (2006), Sevilla, Ayuntamiento de Alcalá del Río.

Ferrer Albelda, E. y García Fernández, F.J. (2008): "Cerámica turdetana", en D. Bernal y A. Ribera (eds.), Cerámicas hispanorromanas. Un estado de la cuestión: 201-220. Cádiz, Universidad de Cádiz.

Ferrer Albelda, E.; García Vargas, E. y García Fernández, F.J. (2008): “Inter Aestuaria Baetis. Espacios naturales y territorios ciudadanos prerromanos en el Bajo Guadalquivir". Mainake XXX: 217-246. 
García Fernández, F.J. (2017): "La herencia de Argantonio: cambios y estrategias en el Tarteso postcolonial", en S. Celestino y E. Rodríguez (eds.), Territorios comparados: los valles del Guadalquivir, el Guadiana y el Tajo en época tartésica: 147-173. Mérida, IAM-CSIC.

García Fernández, F.J. y Del Espino Hidalgo, B. (2019): "Doce yacimientos para el conocimiento del 'Reino de Tartessos'. El Decreto 3833/1973: biografía de una declaración no consumada". Lvcentvm 38: 89-110. doi:<http://dx.doi.org/10.14198/LVCENTVM2019.38.04>

García Fernández, F.J. y García Vargas, E. (2012): “Los hornos alfareros de tradición fenicia en el valle del Guadalquivir y su perduración en época romana: aspectos tecnológicos y sociales". Spal 21: 9-38. doi:<http://dx.doi.org/10.12795/spal.2012.i21.01>.

García Fernández, F.J. y González Acuña, D. (2007): "Secuencias estratigráficas y contextos culturales de la Sevilla prerromana", en M. Bendala y M. Belén (eds.), Actas del V Congreso de Historia de Carmona. El nacimiento de la ciudad: la Carmona protohistórica: 525-566. Carmona (2005), Carmona, Universidad de Sevilla-Ayuntamiento de Carmona.

García Fernández, F.J.; Albuquerque, P. y Guillén Rodríguez, L. (e.p.): “Cerro Macareno (La Rinconada, Sevilla): nuevas investigaciones en un yacimiento paradigmático del Guadalquivir protohistórico", en Actas del IX Congreso Internacional de Estudios Fenicios y Púnicos. Mérida (2018), Mérida.

González García, F.; González Vilches, M.C. y García Ramos, G. (1985): "Productos de alfarería de Cerro Macareno (Sevilla): naturaleza y procedencia de las ánforas y otros objetos cerámicos. Siglos VIII a III a.J.C.”. Noticiario Arqueológico Hispánico 21: 157-174.

González Vilches, M.C.; González García, F. y García Ramos, G. (1985a): "Materias primas y datos tecnológicos de piezas cerámicas antiguas del yacimiento arqueológico de Cerro Macareno (Sevilla) (I)". Boletín de la Sociedad Española de Cerámica y Vidrio 24 (3): 173-186.

González Vilches, M.C.; García Ramos, G. y González García, F. (1985b): "Materias primas y datos tecnológicos de piezas cerámicas antiguas del yacimiento arqueológico de Cerro Macareno (Sevilla) (II)". Boletín de la Sociedad Española de Cerámica y Vidrio 24 (4): 219-232.

González Vilches, M.C.; González García, F.; García Ramos, G. y González Rodríguez, M. (1988):
"Estudio arqueométrico de pigmentos de algunas piezas cerámicas de Cerro Macareno (Sevilla)". Boletín de la Sociedad Española de Cerámica y Vidrio 27 (2): 73-80.

Jiménez Sancho, A. (2010): “Prospección Arqueológica Superficial en sectores urbanizables. P.G.O.U. de La Rinconada (Sevilla)". Anuario Arqueológico de Andalucía 2006: 3797-3809.

Luzón Nogué, J.Mª (1973): Excavaciones en Itálica. Estratigrafía en el Pajar de Artillo (Campaña 1970). Madrid, Ministerio de Educación y Ciencia.

Martín de la Cruz, J.C. (1976): "El corte F del Cerro Macareno. La Rinconada (Sevilla)". Cuadernos de Prehistoria y Arqueología de la Universidad Autónoma de Madrid 3: 9-31.

Pellicer Catalán, M. (1978): “Tipología y cronología de las ánforas prerromanas del Guadalquivir, según el Cerro Macareno (Sevilla)". Habis 9: 365-400.

Pellicer Catalán, M. (1982): “Las cerámicas del mundo fenicio en el Bajo Guadalquivir: evolución y cronología según el Cerro Macareno (Sevilla)", en Phöinizier im Westen: 371-406. Mainz am Rhein, Philipp Von Zabern.

Pellicer Catalán, M.; Bendala Galán, M. y Escacena Carrasco, J.L. (1983): El Cerro Macareno. Madrid, Ministerio de Educación y Ciencia.

Ponsich, M. (1974): Implantation rurale antique sur le Bas-Guadalquivir, vol. 1. París, E. de Boccard.

Prados Martínez, F. (2003): Introducción al estudio de la arquitectura púnica. Madrid, Universidad Autónoma de Madrid.

Prados Martínez, F. (2007): "La edilicia púnica y su reflejo en la arquitectura ibérica: materiales, aparejos y técnicas constructivas". Pallas 75: 9-36.

Ruiz Mata, D. y Córdoba Alonso, I. (1999): “Los hornos turdetanos del Cerro Macareno. Cortes H.I y H.II", en XXIV Congreso Nacional de Arqueologia: 95-105. Cartagena (1997), Cartagena, Gobierno de la Región de Murcia-Instituto de Patrimonio Histórico.

Ruiz Mata, D. y Vallejo Sánchez, J.I. (2002): “Continuidad y cambio durante el siglo VI a.C. Las cerámicas del Corte $\mathrm{C}$ del Cerro Macareno (La Rinconada, Sevilla)". Spal 11: 197-218. doi: $<$ http:// dx.doi.org/10.12795/spal.2002.i11.10>.

Serrano Martín, T. (2015): La arquitectura doméstica de época turdetana en el Bajo Guadalquivir. Tesis Doctoral, Universidad de Sevilla. <http://hdl. handle.net/11441/34619> [08/10/2019]. 
